\title{
A process-based, climate-sensitive model to derive methane emissions from natural wetlands: Application to five wetland sites, sensitivity to model parameters, and climate
}

\author{
Bernadette P. Walter ${ }^{1}$ \\ Columbia University/NASA Goddard Institute for Space Studies, New York \\ Martin Heimann \\ Max-Planck-Institut für Biogeochemie, Jena, Germany
}

\begin{abstract}
Methane emissions from natural wetlands constitute the largest methane source at present and depend highly on the climate. In order to investigate the response of methane emissions from natural wetlands to climate variations, a one-dimensional process-based climate-sensitive model to derive methane emissions from natural wetlands is developed. In the model the processes leading to methane emission are simulated within a one-dimensional soil column and the three different transport mechanisms, diffusion, plant-mediated transport, and ebullition, are modeled explicitly. The model forcing consists of daily values of soil temperature, water table, and net primary productivity, and at permafrost sites the thaw depth is included. The methane model is tested using observational data obtained at five wetland sites located in North America, Europe, and Central America, representing a large variety of environmental conditions. It can be shown that in most cases seasonal variations in methane emissions can be explained by the combined effect of changes in soil temperature and the position of the water table. Our results also show that a process-based approach is needed because there is no simple relationship between these controlling factors and methane emissions that applies to a variety of wetland sites. The sensitivity of the model to the choice of key model parameters is tested and further sensitivity tests are performed to demonstrate how methane emissions from wetlands respond to longer-term climate variations.
\end{abstract}

\section{Introduction}

Methane is one of the important greenhouse gases, contributing about $22 \%$ to the greenhouse effect at present [Lelieveld et al., 1998]. Its atmospheric concentration has increased by a factor of 2.5 since the onset of industrialization and is now $1720 \mathrm{ppbv}$. Since methane has a large radiative effect, one unit mass of $\mathrm{CH}_{4}$ has 21 times the radiative effect of one unit mass of $\mathrm{CO}_{2}$, changes in the atmospheric methane concentration affect the temperature on Earth [Houghton, 1996]. Natural wetlands are the largest methane source at present, contributing about $40 \%$ to the total methane emissions and form a significant nonanthropogenic methane source [Hein et al., 1997]. Furthermore, unlike most other methane sources, methane emissions from natural wetlands depend highly on the climate being influenced by temperature as well as by wetness.

The emission of methane from natural wetlands is a result of biological and physical processes taking place in the soil: methane production by methanogenic bacteria under anaerobic conditions,

\footnotetext{
${ }^{\text {I} F o r m e r l y ~ a t ~ M a x-P l a n c k-I n s t i t u t ~ f u ̈ r ~ M e t e o r o l o g i e, ~ H a m b u r g, ~}$ Germany.
}

Copyright 2000 by the American Geophysical Union.

Paper number 1999GB001204.

0886-6236/00/1999GB001204\$12.00 methane oxidation by methanotrophic bacteria under aerobic conditions, and transport of methane to the atmosphere [e.g. Conrad, 1989]. Numerous studies have been carried out to investigate which factors control these processes. It has been shown that the most dominant determinants are the following.

1. The position of the water table because it determines the extent of the anoxic soil zone, where methane is produced, and the oxic soil zone, where methane is oxidized [e.g. Bartlett and Harriss, 1993; Bubier et al., 1995; Dise et al., 1993; Fowler et al., 1995; Funk et al., 1994; Moore and Roulet, 1993; Morrissey and Livingston, 1992; Sebacher et al., 1986].

2. The soil temperature, since it influences the rates at which microbiological processes such as degradation of organic matter (i.e., the production of substrate for methanogenesis), methane production, and methane oxidation occur [e.g. Baker-Blocker et al., 1977; Bartlett and Harriss, 1993; Bubier et al., 1995; Christensen et al., 1995; Crill et al., 1988; Dise et al., 1993; Fowler et al., 1995; Frolking and Crill, 1994; Kettunen and Kaitala, 1996; Morrissey and Livingston, 1992; Whalen and Reeburgh, 1992].

3. The availability and quality of suitable substrate for methane production. Several authors observed a correlation between factors indicating substrate availability, such as the net primary productivity (NPP), the net ecosystem production (NEP), or the amount of biomass and methane production. Others observed enhanced methane emission after addition of substrate to the soil or from sites with a higher substrate quality [e.g. Bridgham and 
Richardson, 1992; Klinger et al., 1994; Morrissey and Livingston, 1992; Valentine et al., 1994; Whiting et al., 1991; Whiting and Chanton. 1992; Whiting and Chanton, 1993].

4. The pathways by which methane is transported to the atmosphere can be crucial for determining the fraction of produced methane that is emitted into the atmosphere. Transport can proceed by molecular diffusion, ebullition, and transport through the stems of vascular plants [Conrad, 1989]. Depending on the prevailing soil conditions, the occurrence of one or more of those mechanisms can significantly alter the amount of emitted methane: Ebullition can bring methane much faster to the water table than diffusion and thus increase methane emission [Bartlett et al., 1990; Boon and Sorrell, 1995; Devol et al., 1990; Wassmann et al., 1992]. Plant-mediated transport can enhance methane emission through bypassing the often existing oxic top soil layer and thereby avoiding methane oxidation there [Bartlett et al., 1992; Boon and Sorrell, 1995; Bubier et al., 1995; Chanton et al., 1992a; Chanton and Dacey, 1991; Dacey and Klug, 1979; Happell et al., 1993; Holzapfel-Pschorn et al., 1986; Morrissey and Livingston, 1992; Schimel, 1995; Shannon et al., 1996; Shannon and White, 1994; Torn and Chapin III, 1993; Waddington et al., 1996; Whiting and Chanton, 1992; Yavitt and Knapp, 1995]. However, atmospheric oxygen can be conducted by vascular plants down to the rooting zone. Therefore, in water saturated soils covered by vascular plants, a small oxic zone establishes around the root tips leading to methane consumption there [Gerard and Chanton, 1993; Holzapfel-Pschorn et al., 1986; Schipper and Reddy, 1996; Schütz et al., 1989].

These controlling factors are not independent of each other; for example, higher temperatures can lead to lower water table levels due to enhanced evapotranspiration. Thus higher temperatures will lead only to higher methane emissions, if the soil stays water saturated. For example Roulet et al. [1992] found that temperature explained the variances in methane emissions as long as the soil was water saturated, but as soon as the water table decreased below the soil surface, methane emissions were determined by the position of the water table. Valentine et al. [1994] observed that the temperature dependence of methane production increased with increasing amount and quality of substrate at sites that were substrate limited. Hence the controlling factors are not independent of each other, and their relative importance depends on the conditions present in the wetland. Therefore different factors are determining at different times and sites. Thus the results of these studies are site-specific and depend on the situations prevailing during the measurements.

Some of the authors cited above have also developed simple models to predict methane emissions from a wetland site. These models are based on observed empirical relationships between the factors controlling methane emissions and methane fluxes and, as discussed above, are not capable of simulating methane emissions from other wetland sites and under conditions different from those on which the models are based. Besides the model described and used in this article, there are two models in the literature using a more process-based approach, one by Cao et al. [1996] and one by Potter [1997]. Cao et al. [1996] simulate the carbon dynamics in the soil and derive the methane production rate as a function of the amount of decomposed organic carbon, the position of the water table, and the temperature. Methane emission rates are calculated as the difference between methane production and oxidation rates. The model is applied on the global scale, but it has not been tested against data from any wetland site. The model by Potter [1997] is based on an ecosystem cycling model and simulates methane production rates from a microbial production ratio of $\mathrm{CO}_{2}$-to- $\mathrm{CH}_{4}$ that changes as a function of the water table depth. The three different transport mechanisms are modeled as simple functions of methane production, water table, and ecosystem type. However, the model when tested against data from one field site does not reproduce observations very well.

The objective of the present work is to provide a model that can be applied to simulating methane emissions from different wetland types in various regions as a function of the prevailing climate. The idea is to have a tool that can be used to study climatedependent variations of methane emissions from natural wetlands on a larger scale (e.g., global scale) as it has already been done to investigate interannual variations of methane emissions from natural wetlands under present-day climatic conditions [Walter, 1998]. Therefore the model used here is a more process-based, climatesensitive model than others. In the remainder of this paper we give an extended description of a slightly modified version of the methane emission model briefly described by Walter et al. [1996] and show the results of tests of the model against data from five different test sites located in North America, Europe, and Central America, representing a large variety of environmental conditions. In addition, we present the results of sensitivity studies of the model and demonstrate how methane emissions from natural wetlands might change under possible climatic conditions in the future.

\section{Model Description}

Since the processes leading to methane emission from wetlands occur in the soil, the following model structure is chosen (Figure 1): A one-dimensional soil column is divided into $1 \mathrm{~cm}$ thick parallel layers. The position of the water table is assumed to be the boundary between the anoxic and the oxic soil zone. Methane is produced in the layers below the water table. The methane production rate is calculated as a function of the soil temperature and the NPP, which is assumed to be a measure for substrate availability. In the layers above the water table, methane is consumed. The methane oxidation rate is calculated using the Michaelis-Menten equation. Oxidation is also a function of the soil temperature. Three different transport mechanisms are modeled explicitly: (1) molecular diffusion through the water or air filled soil pores and the standing water, if the water table is above the soil surface, (2) transport by ebullition from the depth where bubbles are formed up to the water table, and (3) transport through plants from soil layers above the rooting depth directly up to the atmosphere. Transport of gas due to moving water table is not considered. The model forcing consists of daily values of the position of the water table, the soil temperature profile, and the NPP. The model output is methane fluxes to the atmosphere and methane concentration profiles in the soil, both obtained on a daily basis by numerically solving the one-dimensional continuity equation within the entire soil/water column:

$$
\begin{aligned}
\frac{\partial}{\partial t} C_{C H_{4}}(t, z)= & -\frac{\partial}{\partial z} F_{\text {diff }}(t, z)+Q_{\text {ebull }}(t, z)+Q_{p l a n t}(t, z)+(1) \\
& R_{\text {prod }}(t, z)+R_{\text {oxid }}(t, z)
\end{aligned}
$$

where $\mathrm{C}_{\mathrm{CH}_{4}}(\mathrm{t}, \mathrm{z})$ is the methane concentration at time $\mathrm{t}$ and depth $z, F_{\text {diff }}(t, z)$ is the diffusive flux of methane through the soil, 


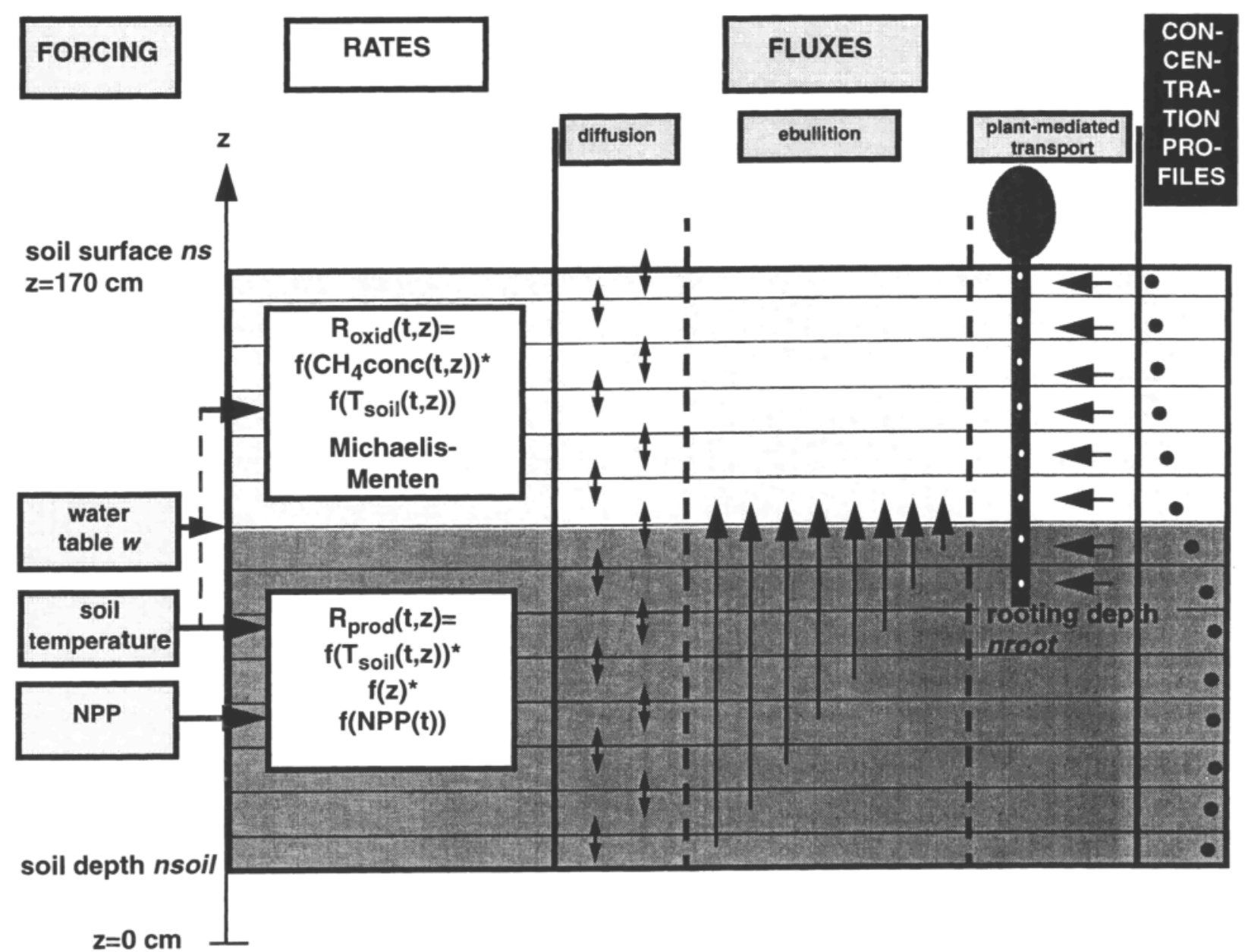

Figure 1. Schematic representation of the model structure. The one-dimensional soil column is divided into $1 \mathrm{~cm}$ thick parallel layers. The forcing consists of daily records of the water table, the soil temperature, and the NPP. Methane production occurs in the soil zone between the soil depth nsoil and the water table w, which can be either below or above the soil surface ns. The methane production rate $R_{\text {prod }}(t, z)$ is a function of the soil temperature $T_{\text {soil }}(t, z)$ and the NPP, which is taken as a measure for substrate availability. Methane oxidation is confined to the soil layers between the water table and the soil surface. The methane oxidation rate $R_{\text {oxid }}(t, z)$ follows Michaelis-Menten kinetics and is a function of the soil temperature $T_{\text {soil }}(t, z)$. Transport proceeds by (1) molecular diffusion through the soil pores, (2) ebullition, which is the formation of gas bubbles in the water saturated layers and their ascent to the water table, and (3) plant-mediated transport from layers above the rooting depth nroot to the atmosphere. The model calculates methane fluxes to the atmosphere and methane concentration profiles in the soil on a daily basis.

$\mathrm{Q}_{\text {ebull }}(\mathrm{t}, \mathrm{z})$ and $\mathrm{Q}_{\text {plant }}(\mathrm{t}, \mathrm{z})$ represent sinks due to ebullition and plant-mediated transport, respectively. $R_{\text {prod }}(t, z)$ is the methane production rate, while $R_{\text {oxid }}(t, z)$ denotes the methane oxidation rate In the following, each of the terms will be described in detail.

\subsection{Methane Production Rate $\mathbf{R}_{\text {prod }}$}

Methane production is calculated in all soil layers below the water table. There are two factors controlling the rate of methanogenesıs (1) the availability and quality of suitable substrate which onginates mainly from root exudates, dead fine roots, and the 1nput of plant litter and (2) temperature [e.g. Conrad, 1989; Heyer, 1990] We consider only fresh organic matter to be suitable substrate for methanogenesis [e.g. Chanton et al., 1995; Bridgham and Richardson, 1992]. Hence, the availability of substrate is assumed to be connected with NPP, which is used as a measure for the production of fresh organic carbon in soil. Its variation with time $f_{i n}(t)$ has been parameterized in the following way: It is calculated as a function of the variation of the NPP with time, $f_{N P P}(t)$, which is derived from the simulated NPP(t) of the global terrestrial carbon cycle model Biosphere-Energy Transfer and Hydrology (BETHY) [Knorr, 1997] (appendix A). Thus the variation of substrate availability with time $t, f_{i n}(t)$, is parameterized as

$$
f_{i n}(t)=1+\frac{f_{N P P}(t)}{N_{\text {max }}},
$$

where $\mathrm{NPP}_{\max }$ denotes the annual maximum value of the NPP ( $\mathrm{g}$ $\mathrm{C} \mathrm{m}^{-2} \mathrm{month}^{-1}$ ); that is, only relative changes in the NPP with time are considered. It is assumed that the seasonality of the NPP is essentially the same for wetland and nonwetland ecosystems Therefore this seasonality has been taken from calculations with the BETHY model, which calculate NPP for a mixture of vegeta- 
tion types derived from the vegetation map of Wilson and Henderson-Sellers [1985], with wetlands as one possibility. This particular type is distinguished by an absence of water stress, while values for photosynthetic capacity are assumed to be the same as those for C3 grasses [Beerling and Quick, 1995]. The availability of potential substrate for methanogenesis also decreases with increasing soil depth $\mathrm{z}$, because the sources of fresh organic material are located either at the soil surface or in the upper soil layers. There are several studies where methane production potentials in the soil have been measured [Roulet et al., 1993; Valentine et al., 1994; Saarnio et al., 1997; Kettunen et al., 1999]. The vertical pattern of methane production potentials is assumed to be linked with substrate availability [Valentine et al., 1994]. In addition, it depends on vegetation. Under saturated conditions most of the observed profiles show an exponential decrease of methane production potentials with depth, whereby most of the production occurs in the upper $50 \mathrm{~cm}$ of the soil, and below 100 $\mathrm{cm}$, methane production becomes insignificant. Therefore, in vegetated soils, it is assumed that the availability of substrate $f_{\text {org }}(z)$ is constant throughout the rooting zone because fresh litter and probably also root exudates represent a major source of substrate. Below the rooting depth, $\mathrm{f}_{\text {org }}(\mathrm{z})$ decreases exponentially with depth $z$ reaching a value of about $10 \%$ at $20 \mathrm{~cm}$ and almost 0 at 50 $\mathrm{cm}$ below the rooting depth:

$$
\mathrm{f}_{\text {org }}(\mathrm{z})=\left(\begin{array}{ll}
1 & \text { nroot } \leq \mathrm{z} \leq \mathrm{ns} \\
\mathrm{e}^{(-\mid \mathrm{z}-\text { nroot } \mid) /(10 \mathrm{~cm})} & \text { nsoil } \leq \mathrm{z}<\text { nroot }
\end{array},\right.
$$

nroot denotes the rooting depth, ns denotes the soil surface, and nsoil denotes the soil depth, i.e., the lower boundary of the active layer. In unvegetated soils the vertical distribution of substrate $f_{\text {org }}(z)$ is assumed to decrease exponentially from the soil surface to the lowest soil layer. Here, $f_{\text {org }}(z)$ has been chosen in a way that at $50 \mathrm{~cm}$ below the soil surface $f_{\text {org }}(z)$ is about $10 \%$ of the value at the soil surface and becomes insignificant below $100 \mathrm{~cm}$ soil depth:

$$
f_{\text {org }}(z)=0.857 e^{(-|z-n s|) /(20 c m)} \quad \text { nsoil } \leq z \leq n s
$$

Possible methane production from soil layers deeper than $50 \mathrm{~cm}$ below the rooting depth (Equation (3)) or $100 \mathrm{~cm}$ soil depth (Equation (4)) is neglected in the model because it is assumed to be very small. This might lead to slightly underestimating total methane production from wetlands with peat layers deeper than 1 $m$, particularly in winter when soil temperatures are higher in deeper soil layers. Using information on the depth of peat layers in different wetlands, if available, could help to improve this in the future. The variation of the methane production rate with temperature is formulated in the following way. $A Q_{10}$ dependence is chosen using a $Q_{10}$ value of 6 lying within the range of observed $Q_{10}$ values ranging from 1.7 to 16 [Dunfield et al., 1993; Valentine et al., 1994; Westermann, 1993]. It is assumed that this temperature function includes both the temperature dependence of the production of substrate for methanogenesis and that of methane production. The temperature function describes the response to the seasonal variation of the soil temperature $T(t, z)$ at time $t$ and depth $z$ relative to the annual mean soil temperature $T_{\text {mean }}$ at the site. Consequently, the methane production rate $R_{\text {prod }}(t, z)$ at time $t$ and depth $\mathrm{z}$ is described as

$$
R_{\text {prod }}(t, z)=R_{0} f_{\text {org }}(z) f_{i n}(t) f(T) Q_{10}^{\frac{T(t, z)-T_{\text {mean }}}{10}}
$$

$R_{0}$ is a constant rate factor expressed in units of $\mu \mathbf{M ~ h}^{-1}$ $\left(1 \mathrm{M}=1 \mathrm{~mol} \mathrm{~L}^{-1}\right)$. It is a measure for the absolute substrate availability and quality (since $f_{\text {in }}(t)$ and $f_{\text {org }}(z)$ describe only relative changes in the substrate availability with time and depth). Since in the model these quantities are not simulated explicitly, the parameter $\mathbf{R}_{\mathbf{0}}$ is a tuning parameter which has to be adjusted to each data set; that is, the value of $R_{0}$ is chosen to get the correct amplitude of simulated methane emissions. As shown in section 4.1 , it only changes the amplitude but not the pattern of the modeled methane emissions. The function $f(T)$ is a step function being 1 if $T(t, z)$ is above $0^{\circ} \mathrm{C}$, and 0 all other times. This is equivalent to the assumption that there is no methane production at subzero temperatures. There are a few studies that report winter methane emissions [Dise, 1992; Melloh and Crill, 1996], and at least one study that reports methane production at temperatures down to $-5^{\circ} \mathrm{C}$ [Clein and Schimel, 1995], but it seems that methane production at subzero temperatures is small. In some of these studies it is also suggested that part of the methane emitted in winter is methane produced already in summer and stored in the soil. Furthermore, there are several studies showing that methane emissions during the wintertime are significantly lower than during the growing season [e.g. Whalen and Reeburgh, 1992; Shannon and White, 1994].

The chemical conditions in the soil can also affect methanogenesis [e.g. Conrad, 1989]. For example, pH conditions can be important. In addition, methanogenesis requires the absence of competing electron acceptors like sulfate $\left(\mathrm{SO}_{4}{ }^{2-}\right)$, nitrate $\left(\mathrm{NO}_{3}{ }^{-}\right)$, or ironIII $\left(\mathrm{Fe}^{3+}\right)$ and a redox potential below $-200 \mathrm{mV}$. In addition, the availability of nutrients can enhance the productivity [Schlesinger, 1991]. These effects are not taken into account in the model. The potential effect of a disadvantageous $\mathrm{pH}$ and the availability of nutrients on methane production rates is included in the parameter $\mathbf{R}_{\mathbf{0}}$. Concerning the effect of competing electron acceptors and the redox potential on methane production, it is assumed in the model that the timescale, on which such effects are inhibiting methane production, is small compared to the timescale of the model, being 1 day.

\subsection{Methane Oxidation Rate $\mathbf{R}_{\text {oxid }}$}

Methane oxidation is calculated in all soil layers above the water table. The methane oxidation rate $R_{\text {oxid }}(t, z)$ at time $t$ and depth $\mathrm{z}$ is assumed to follow Michaelis-Menten kinetics [Bender and Conrad, 1992]. In addition, it depends on the soil temperature with observed $\mathrm{Q}_{10}$ values lying in the range between 1.4 and 2.1 [Dunfield et al., 1993; Knoblauch, 1994]. In the model, $Q_{10}$ for oxidation has been chosen to be 2 . Thus $R_{\text {oxid }}(t, z)$ is calculated from

$$
R_{\text {oxid }}(t, z)=-\frac{V_{\max } C_{C H 4}(t, z)}{K_{m}+C_{C H 4}(t, z)} Q_{10}^{\frac{T(t, z)-T_{\text {mean }}}{10}},
$$

where $K_{m}$ and $V_{\max }$ are the Michaelis-Menten coefficients. $\mathrm{C}_{\mathrm{CH} 4}(\mathrm{t}, \mathrm{z})$ denotes the methane concentration $(\mu \mathrm{M})$ at time $\mathrm{t}$ and depth $\mathrm{z}$, whereas $\mathrm{T}_{\text {mean }}$ is the annual mean soil temperature $\left({ }^{\circ} \mathrm{C}\right)$. The observed values for $\mathrm{K}_{\mathrm{m}}$ lie between 1 and $5 \mu \mathrm{M}$ [Dunfield et al., 1993; Knoblauch, 1994], while $\mathrm{V}_{\max }$ has been found to cover the range of about 5-50 $\mu \mathrm{M} \mathrm{h}^{-1}$ [Dunfield et al., 1993; Knoblauch, 1994; Krumholz et al., 1995; Moore and Dalva, 1997; Sundh et al., 1994; Watson et al., 1997]. In the model, $\mathrm{K}_{\mathrm{m}}$ and $\mathrm{V}_{\max }$ have been set to $5 \mu \mathrm{M}$ and $20 \mu \mathrm{M} \mathrm{h}^{-1}$, respectively. During the tests of 
the model against data sets from various wetlands, it turned out that a $\mathrm{V}_{\max }$ value of $20 \mu \mathrm{M} \mathrm{h}^{-1}$ cannot be used at all sites. Therefore, at sites where a value of $20 \mu \mathrm{M} \mathrm{h}^{-1}$ does not yield satisfactory results, we choose another value for $\mathrm{V}_{\max }$; the resulting values lying in the range from 3 to $45 \mu \mathrm{M} \mathrm{h}^{-1}$. In the model, methane oxidation occurs only in the unsaturated soil layers. It has been observed that in ecosystems with a water table being several decimeters above the soil surface, there can be, due to turbulent diffusion, enough oxygen in the standing water column to make methane oxidation possible (D.W. Valentine, personal communication, 1997; W.S. Reeburgh, personal communication, 1997). Since it is not known if this effect is of general importance in different wetland types, it has not been incorporated into the model.

\subsection{Diffusion $F_{\text {diff }}$}

The diffusive flux $F_{\text {diff }}(t, z)$ is calculated using Fick's first law:

$$
\mathrm{F}_{\text {diff }}(\mathrm{t}, \mathrm{z})=-\mathrm{D}_{\mathrm{CH} 4}(\mathrm{z}) \frac{\partial}{\partial \mathrm{z}} \mathrm{C}_{\mathrm{CH} 4}(\mathrm{t}, \mathrm{z}),
$$

where $\mathrm{D}_{\mathrm{CH} 4}(\mathrm{z})$ is the diffusion coefficient of methane at depth $\mathrm{z}$ and $\mathrm{C}_{\mathrm{CH} 4}(\mathrm{t}, \mathrm{z})$ is the methane concentration at time $\mathrm{t}$ and depth $\mathrm{z}$. Since in the soil diffusion occurs only through the soil pores, the diffusion coefficient is obtained from

$$
\mathrm{D}_{\mathrm{CH} 4}(\mathrm{z})=\mathrm{D}_{\mathrm{i}} \quad 0.66 \mathrm{f}_{\text {coarse }},
$$

which is the so-called Penman relation [Hillel, 1982], using a tortuousity coefficient, which has been set to 0.66 , suggesting that the distance covered by diffusion is about two-thirds of the length of the real average path. In the unsaturated soil layers, $D_{i}$ is the diffusion coefficient of methane in bulk air, which is $0.2 \mathrm{~cm}^{2} \mathrm{~s}^{-1}$ [D'Ans and Lax, 1967], while in the water-saturated soil layers $\mathrm{D}_{\mathrm{i}}=10^{-4} 0.2 \mathrm{~cm}^{2} \mathrm{~s}^{-1}$ [Scheffer and Schachtschabel, 1982]. The factor $f_{\text {coarse }}$ denotes the relative volume of the coarse pores; that is, we assume that diffusion proceeds mainly through the large pores. To solve the diffusion equation, the Crank-Nicolson scheme [Press et al., 1992] is used. The methane concentration values are defined in the middle of each layer, whereas the diffusion coefficients are defined at the layer boundaries. The following boundary conditions are chosen:

$$
\frac{\partial}{\partial z} \mathrm{C}_{\mathrm{CH} 4}(\mathrm{t}, \mathrm{z}=\text { nsoil })=0
$$

at the lower boundary nsoil and

$$
\mathrm{C}_{\mathrm{CH} 4}(\mathrm{t}, \mathrm{z}=\mathrm{u}+4 \mathrm{~cm})=\mathrm{C}_{\mathrm{atm}}
$$

at the upper boundary $u$, which is either the water table $w(t)$ (if $w(t)>n s)$ or the soil surface ns. $C_{a t m}$ is the atmospheric methane concentration of $0.076 \mu \mathrm{M}$. At the water-air interface the methane concentrations in both phases are assumed to be in equilibrium. Hence their ratio is specified by the Bunsen solubility coefficient.

\subsection{Ebullition $Q_{\text {ebull }}$}

As soon as the methane concentration in a layer exceeds a certain threshold concentration $\mathrm{C}_{\text {thresh }}$, bubbles are formed. Since there is usually enough condensation nuclei in the soil and owing to the occurrence of other gases such as nitrogen $\left(\mathrm{N}_{2}\right), \mathrm{C}_{\text {tresh }}$ usually is significantly lower than the saturation concentration (which is $1875 \mu \mathrm{M}$ at $10^{\circ} \mathrm{C}$ [Kaltofen et al., 1975]). In vegetated soils, for example, the concentration of $\mathrm{N}_{2}$ was reported to be higher than in unvegetated soils [Chanton and Dacey, 1991]. Thus, according to Chanton and Dacey [1991], Shannon et al. [1996], and HolzapfelPschorn et al. [1986], we assume that $\mathrm{C}_{\text {tresh }}$ is lower at vegetated sites than at unvegetated sites. In the model it is assumed that bubble formation occurs at methane concentrations between 500 and $1000 \mu \mathrm{M}$ at totally vegetated and unvegetated soils, respectively, being equivalent to a mixing ratio of $27-53 \%$ of methane in the bubble (at $10^{\circ} \mathrm{C}$ ). Thus the threshold concentration for bubble formation is calculated from

$$
C_{\text {thresh }}=C_{\min }\left(1+\frac{P_{\text {unveg }}}{100}\right) \text {, }
$$

where $\mathrm{C}_{\min }$ is the concentration at which bubble formation occurs, if the site is totally vegetated $(500 \mu \mathrm{M})$ and $P_{\text {unveg }}$ is the percentage of unvegetated, bare soil. In order to determine the flux $F_{\text {ebull }}(t)$ of methane reaching the water table $w(t)$ at time $t$ in the form of gas bubbles, the rate $Q_{\text {ebull }}(t, z)$ at which methane in the form of bubbles is removed from depth $\mathrm{z}$ is calculated:

$$
\mathrm{Q}_{\text {ebull }}(\mathrm{t}, \mathrm{z})=-\mathrm{k}_{\mathrm{e}} \mathrm{f}\left(\mathrm{C}_{\mathrm{CH} 4}\right)\left(\mathrm{C}_{\mathrm{CH}_{4}}(\mathrm{t}, \mathrm{z})-\mathrm{C}_{\text {thresh }}\right) \text {, }
$$

where $k_{e}$ is a rate constant of the unit $1 h^{-1}$ and $f\left(\mathrm{C}_{\mathrm{CH} 4}\right)$ is a step function taking the value 1 , if the methane concentration $\mathrm{C}_{\mathrm{CH} 4}(\mathrm{t}, \mathrm{z})$ is greater than $\mathbf{C}_{\text {thresh }}$, and $\mathbf{0}$ otherwise. In the layers above the water table, $Q_{\text {ebull }}(t, z)$ is 0 . Bubbles are assumed to reach the water table within one model time step being 1 hour. This assumption is supported by the fact that wetland soils are generally very porous, the relative pore volume being often greater than $90 \%$ [Scheffer and Schachtschabel, 1982], and the finding that the velocity of bubbles ascending in pure water lies in the order of 1$10 \mathrm{~cm} \mathrm{~s}^{-1}$ [e.g. Shafer and Zare, 1991]. Thus the ebullitive flux $F_{\text {ebull }}(t)$ is obtained by integrating $Q_{\text {ebull }}(t, z)$ over the whole water saturated zone:

$$
F_{\text {ebull }}(t)=\int_{n s o i l}^{w(t)} Q_{e b u l l}(t, z) d z
$$

where nsoil is the lower boundary of the active layer and $w(t)$ is the water table. If the water table is at or above the soil surface, $F_{\text {ebull }}(t)$ contributes directly to the methane flux into the atmosphere. Otherwise, the amount of methane rising to the water table in the form of bubbles is added to the methane concentration in the lowest unsaturated soil layer. While the effect of subzero temperatures on methane production is accounted for in the model (Equation (5)), the soil frost state does not affect diffusion (Equation (7)) or ebullition (Equation (13)). However, winter methane production is very low in the model, so that considering a further inhibiting effect on winter methane flux is not expected to have a significant effect on model results.

\subsection{Plant-Mediated Transport $Q_{\text {plant }}$}

The occurrence of vascular plants provides an effective mechanism by which methane can be transported to the atmosphere [e.g. Chanton et al., 1992a; Schimel, 1995; Shannon et al., 1996]. Moreover, oxygen can be conducted down to the roots this way establishing a small aerobic region in the rhizosphere [Gerard and Chanton, 1993; Holzapfel-Pschorn et al., 1986; Schipper and Reddy, 1996; Schütz et al., 1989]. The results from several studies of plant-mediated transport suggest that the main emission pathway is by molecular diffusion or effusion through the plant stems [Chanton et al., 1992a; Chanton et al., 1992b; Happell et al., 1993; Nouchi and Mariko, 1993; Shannon et al., 1996]. Conse- 
quently, the flux of methane through plants is assumed to be proportional to the concentration gradient between the soil and the atmosphere, and since the atmospheric methane concentration is very small compared to soil methane concentrations, the plantmediated flux is proportional to the methane concentration in the soil. Nouchi and Mariko [1993] found a linear relationship between methane emission rates through plants and pore water methane concentrations. Hence the rate $Q_{\text {plant }}(t, z)$ at which methane is removed by plants from depth $\mathrm{z}$ at time $\mathrm{t}$ is calculated from

$$
Q_{\text {plant }}(t, z)=-k_{p} \quad T_{\text {veg }} f_{\text {root }}(z) f_{\text {grow }}(t) C_{\mathrm{CH}_{4}}(t, z) \text {, }
$$

where $k_{p}$ is a rate constant of the unit $0.01 h^{-1}$ and $T_{\text {veg }}$ is a factor describing the quality of plant-mediated transport at a site, depending on the density of plant stands and the plant types. The range of $T_{v e g}(0-15)$ was derived from studies where information on vegetation and/or the fraction of plant mediated transport was available, and both methane emissions and methane concentration profiles in the soil were observed, as it was the case at sites 1 and 2 [Shannon and White, 1994; Shannon et al., 1996; Dise, 1993]. At sites where the predominant plant types and their capability of conducting gas are known, $\mathrm{T}_{\mathrm{veg}}$ is derived from that knowledge. Otherwise, we consider shrubs not contributing to plant-mediated transport and trees being poor, and grasses and sedges being good gas transporters [Walter, 1998]. The function $f_{\text {root }}(z)$ represents the vertical distribution of roots in the soil. It is assumed to decrease with depth, and for the sake of simplicity, we choose a linear relationship between root biomass and soil depth $\mathrm{z}$ :

$$
\mathrm{f}_{\text {root }}(\mathrm{z})=2 \frac{\mathrm{z}-\text { nroot }}{\mathrm{ns}-\text { nroot }} \quad \text { nroot } \leq \mathrm{z} \leq \mathrm{ns},
$$

where nroot denotes the rooting depth and ns denotes the soil surface. Below the rooting depth nroot, $f_{\text {root }}(z)$ is 0 . The ability of plants to conduct gas is considered to vary with the growing state of the plants. This assumption agrees well with observations by Schütz et al. [1989], who found that the fraction of methane transported through rice plants increases with the growing maturity of the plants. In the model we use the leaf area index (LAI) as a measure for the growing state $f_{\text {grow }}(t)$ of the plants (appendix $B$ ). Since methane entering the roots of plants has to pass through the small oxic zone around the root tips, a certain fraction $P_{o x}$ of methane is oxidized. There are a few studies examinig rhizospheric oxidation: Schipper and Reddy [1996] determined the fraction of methane consumed by rhizospheric oxidation using two different methods and found values of $65 \pm 24$ and $79 \pm 20 \%$. Schütz et al. [1989] observed that about $90 \%$ of the methane produced was oxidized in cases when plant-mediated transport was the main (97\%) emission pathway, while Gerard and Chanton [1993] obtained values for rhizospheric oxidation between 39 and $98 \%$. Taking into consideration the high variability of observed values, we set $P_{o x}$ to $50 \%$. Finally, the methane flux due to plantmediated transport $F_{\text {plant }}(t, z)$ is calculated from

$$
F_{\text {plant }}(t)=\int_{\text {nroot }}^{n s}\left(Q_{\text {plant }}(t, z)\left(1-P_{\text {ox }}\right)\right) d z,
$$

where ns and nroot are the soil surface and the rooting depth, respectively.

\subsection{Total Methane Emission $F_{\text {tot }}$}

The total methane emission $F_{t o t}(t)$ is calculated by adding all the fluxes from the different transport mechanisms: the diffusive flux $F_{\text {diff }}(t, z=u)$ at the soil/water-atmosphere boundary $u$, the flux due to plant-mediated transport $F_{\text {plant }}(t, z)$, and the ebullitive flux $F_{\text {ebull }}(t, z)$. The latter contributes only to the total flux $F_{\text {tot }}(t)$, if the water table is at or above the soil surface. Hence $F_{\text {tot }}(t)$ is obtained from

$$
F_{\text {tot }}(t)=F_{\text {diff }}(t, z=u)+F_{\text {ebull }}(t)+F_{\text {plant }}(t) .
$$

As mentioned in section 1 , this model differs slightly from the model used by Walter et al. [1996]. While in the earlier version, substrate availability $\mathrm{f}_{\text {org }}(\mathrm{z})$ was constant to a depth of $80 \mathrm{~cm}$ below ground and 0 below that depth, an exponential relationship has been chosen now (Equations (3) and (4)) because it seems to be more realistic (J. Harden, personal communication, 1997) and [Roulet et al., 1993; Valentine et al., 1994; Saarnio et al., 1997; Kettunen et al., 1999]. In the current version the methane oxidation rate $R_{\text {oxid }}(t, z)$ (Equation (6)) is considered to be temperature dependent [Dunfield et al., 1993; Knoblauch, 1994], which was not the case in the earlier version. The threshold concentration for bubble formation $\mathrm{C}_{\text {thresh }}$ (Equation (11)) is now a function of the fraction of unvegetated, bare soil $P_{\text {unveg }}$ [Chanton and Dacey, 1991, Shannon et al., 1996, Holzapfel-Pschorn et al., 1986], while it was considered to be constant $(500 \mu \mathrm{M})$ earlier. In the earlier version of the model it was assumed that a certain fraction of rising gas bubbles are trapped in soil and released only if the water table falls below the depth where they are located or the pore space filled by gas bubbles exceeds a certain limit. Now equilibrium between trapped and released gas bubbles is assumed at any time, so that all gas bubbles formed at a time are immediately transported to the water table (Equation (13)). While in the earlier version of the model, the growing state $f_{\text {grow }}(t)$ of plants was derived from an empirically defined function, it is now calculated from the LAI [Dickinson et al.; 1993] (Equation (14) and appendix B). None of these changes has lead to a significant change in the model results at site 1 where the earlier version was tested. However, these changes were made to get more realistic model results, in particular at sites which are drier than site 1 or where plant-mediated transport is less dominant.

\section{Results and Discussion}

The methane model is tested against observational data from 15 microsites within six wetlands located in North America, Europe, and Central America [Walter, 1998]. The observation periods range from 1 season up to 3 years. Here we discuss results from five microsites within five wetlands, and the data sets used in this study are summarized in Table 1 . At each site, methane emissions were measured about 2-4 times per month, and at two sites $(1,2)$ also methane concentration profiles in the soil were obtained 1-2 times per month. At all sites except site 5 the position of the water table and the soil temperature at different soil depths were observed at least at the same frequency as methane emissions. Since at site 5 the forcing data were not observed, a hydrologic model [Walter, 1998] in combination with the European Center/ Hamburg 4 (ECHAM4) model [Roeckner et al., 1996] is used to run the methane model there. The daily forcing required by the methane model is obtained by a linear interpolation of the observed input data. The NPP is obtained from the BETHY model [Knorr, 1997] for that $1^{\circ}$ by $1^{\circ}$ grid box in which the wetland is located. The parameters soil depth nsoil, rooting depth nroot, and the quality of plant-mediated transport $T_{\text {veg }}$ are chosen based on 
Table 1. Data Sets Used to Test the Model

\begin{tabular}{|c|c|c|c|c|c|}
\hline & 1 & 2 & 3 & 4 & 5 \\
\hline Site & Michigan & Minnesota & Finland & Alaska & Panama \\
\hline Location & $42^{\circ} \mathrm{N}, 84^{\circ} \mathrm{W}$ & $47^{\circ} \mathrm{N}, 93^{\circ} \mathrm{W}$ & $63^{\circ} \mathrm{N}, 31^{\circ} \mathrm{E}$ & $65^{\circ} \mathrm{N}, 148^{\circ} \mathrm{W}$ & $9^{\circ} \mathrm{N}, 80^{\circ} \mathrm{W}$ \\
\hline Wetland Type & ombrotrophic bog & poor fen & oligotrophic pine fen & Arctic tundra & swamp \\
\hline $\begin{array}{l}\text { Dominant } \\
\text { Vegetation }\end{array}$ & $\begin{array}{l}\text { Sphagnum, Scheuch- } \\
\text { zeria palustris }\end{array}$ & $\begin{array}{c}\text { Sphagnum, Carex, } \\
\text { Scheuchzeria } \\
\text { palustris }\end{array}$ & $\begin{array}{l}\text { Sphagnum, Eriopho- } \\
\text { rum vaginatum }\end{array}$ & Sphagnum & $\begin{array}{c}\text { Raphia taedigera } \\
\text { (palm) }\end{array}$ \\
\hline $\mathrm{T}_{\text {mean }},{ }^{\circ} \mathrm{C}$ & 12 & 6.5 & 3.5 & 0 & 27 \\
\hline Reference & $\begin{array}{c}\text { Shannon and White } \\
\text { [1994] }\end{array}$ & Dise [1993] & Saarnio et al. [1997] & $\begin{array}{c}\text { Whalen and Ree- } \\
\text { burgh [1992] }\end{array}$ & Keller [1990] \\
\hline
\end{tabular}

Description of location, wetland type, dominant vegetation, annual mean temperature $T_{\text {mean }}$ and references of the data sets used to test the model.

information about the specific wetland site given by the investigators. The parameter $V_{\max }$ is set to $20 \mu \mathrm{M} \mathrm{h}^{-1}$ in most cases but is adjusted to the data set in situations where a value of $20 \mu \mathrm{M} \mathrm{h}^{-1}$ does not yield optimal results. The values of $\mathrm{V}_{\max }$ used in this study range from 3 to $45 \mu \mathrm{M} \mathrm{h}^{-1}$. It is not clear what causes these differences in methane oxidation rates. Possible candidates are the chemical conditions in soil such as $\mathrm{pH}$ or different populations of methanotrophs having temperature optima which are not optimal for the respective sites. Another reason could be that soil texture and/or soil moisture in the unsaturated soil (i.e., the fraction of soil volume where oxidation can occur) is different. The parameter $R_{0}$ is adjusted to the data set in each case. The values for $R_{0}$ obtained lie between 0.3 and 0.6 at the high-latitude sites and 2.8 at the tropical site. $R_{0}$ varies, as mentioned above, as a function of substrate quantity and quality and the chemical conditions in soil such as redox potential, $\mathrm{pH}$, and the presence of competing electron acceptors. Until now, there is no method to predict $R_{0}$ for different sites, owing to both lack of sufficient data on the study sites and, at least in part, knowledge about the quantitative relationship between all important environmental parameters and $R_{0}$. However, as more data become available, a model like that one proposed by Valentine et al. [1994] and Holland [unpublished] could

Table 2. Site-Specific Model Parameters at the Five Test Sites

\begin{tabular}{cccccc}
\hline Site & $\mathrm{R}_{0}$ & $\begin{array}{c}\mathrm{V}_{\text {max }}, \\
\mu \mathrm{M} \mathrm{h}^{-1}\end{array}$ & $\begin{array}{c}\text { ns-nsoil, } \\
\mathbf{c m}\end{array}$ & $\begin{array}{c}\text { ns-nroot, } \\
\mathrm{cm}\end{array}$ & $\mathrm{T}_{\text {veg }}$ \\
\hline 1 & 0.60 & 45 & 80 & 50 & 15 \\
2 & 0.30 & 20 & 80 & 40 & 4 \\
3 & 0.34 & 20 & 70 & 30 & 12 \\
4 & 0.30 & 3 & thaw depth & 0 & 0 \\
5 & 2.80 & 20 & 128 & 74 & 9 \\
\hline
\end{tabular}

Model parameters used at the five test sites presented in this article: $R_{0}$ (tuning parameter), $\mathrm{V}_{\max }$ (maximum methane oxidation rate), ns-nsoil (soil depth below soil surface), ns-nroot (rooting depth below soil surface), and $\mathbf{T}_{\text {veg }}$ (quality of plant-mediated transport) (see model description). be used to predict $\mathbf{R}_{\mathbf{0}}$ for different sites. For a global application, Walter [1998] used a simple method to derive $\mathbf{R}_{0}$ for different regions as a function of annual mean temperature and total annual NPP. In this article, results of five tests from one station at sites 15 are shown. Table 2 lists the parameters used at the five test sites.

\subsection{Site 1: Michigan}

Figure 2 shows the results of a test of the model at site 1 using data by Shannon and White [1994]. The forcing data are plotted in the lower part, Figure $2 c$ shows the observed position of the water table relative to the soil surface, and Figure $2 \mathrm{~d}$ shows the observed soil temperatures at different soil depths. In Figure 2a the comparison between simulated and observed (the average of 3 chamber measurements \pm 1 standard deviation error bars) methane emissions is shown. When the water table is above the soil surface, the patterns of observed as well as simulated methane emissions are dominated by changes in the soil temperature. This applies to both day-to-day and interannual variations of methane emissions. For example, methane emissions are higher in 1991 than in the two following years because of slightly higher soil temperatures in 1991. As soon as the water table falls below the soil surface, this connection between methane emission and soil temperature is no longer evident. In this situation, methane diffusing through the soil pores is partly oxidized in the unsaturated soil layers. In addition, rising bubbles cannot reach the soil surface anymore and only the deeper roots extend into the water saturated soil zone where high methane concentrations prevail. The consequence of a long period with the water table being below the soil surface can be seen in 1991 when methane emissions drop to smaller values of about $200 \mathrm{mg} \mathrm{m}^{-2} \mathrm{~d}^{-1}$ already in August even though the soil temperature is still high at that time. The reason for this is that the water table stays at depths of about $15 \mathrm{~cm}$ below ground since July 1991. In 1992 and 1993 this drop of methane emissions occurs much later in the year, attributable to wetter conditions. In Figure $2 \mathrm{~b}$ the simulated relative contributions of the three different transport mechanisms diffusion, ebullition, and plant-mediated transport are depicted. At sites covered by vascular plants, as it is the case at site 1 , plant-mediated transport plays an important role during the growing season. Shannon et al. [1996] observed in plant enclosure experiments that $64-90 \%$ of the net methane flux 

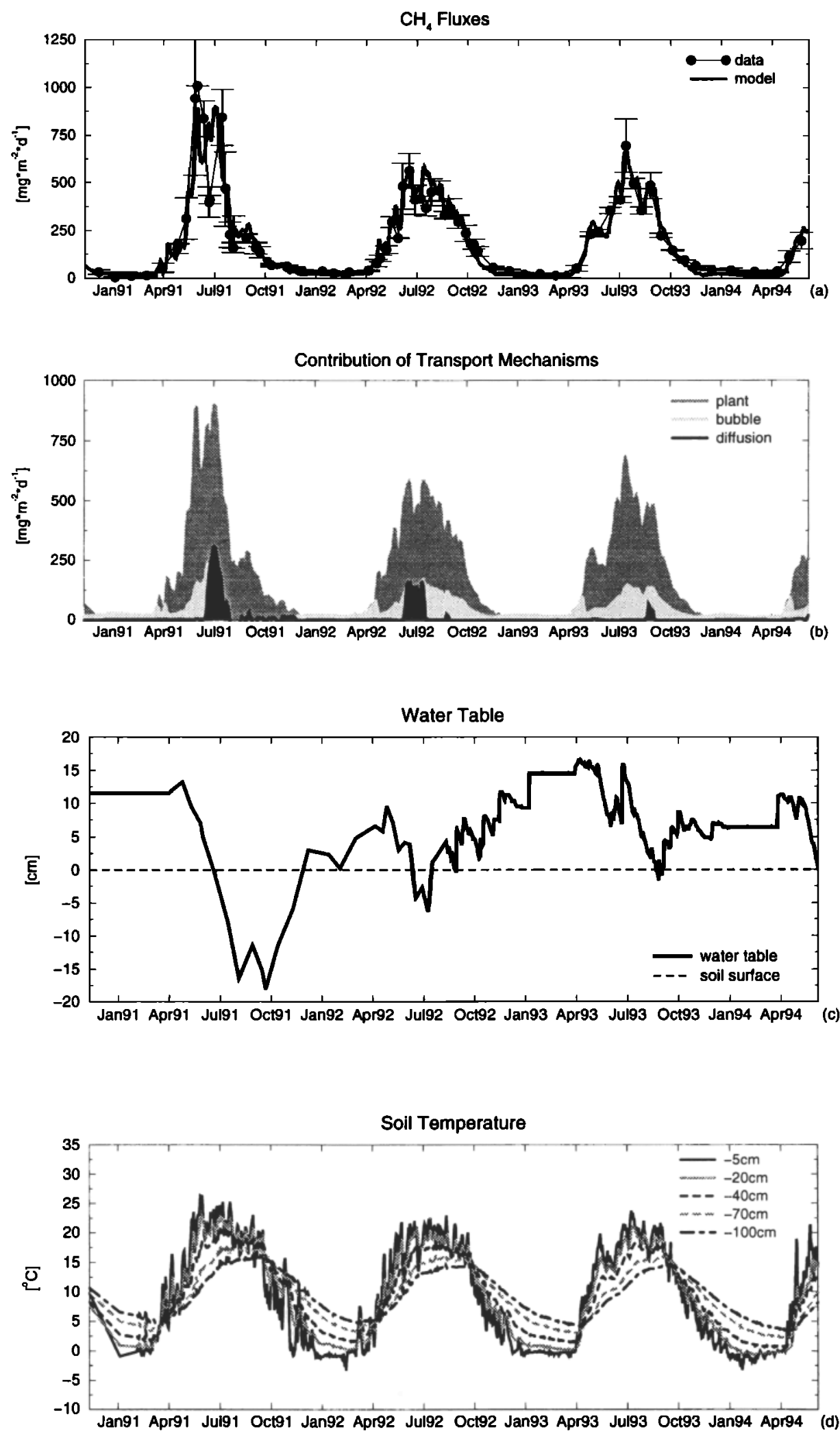

Figure 2. For site 1, (a) comparison between modeled (thick line) and measured (dots with $+/-1$ standard deviation error bars) methane emissions; (b) modeled contributions of the three transport mechanisms, diffusion (black), ebullition (light grey), and plant-mediated transport (dark grey); (c) forcing, observed position of the water table; and (d) forcing, observed soil temperature at different soil depths (observational data from Shannon and White [1994]). 
was emitted through Scheuchzeria palustris. The model results are in good agreement with this finding (Figure 2b). Ebullition occurs only at times when the water table is above the soil surface. Diffusion plays only a role if the water table is below the soil surface. For example, immediately after the fall of the water table below the soil surface in June 1991, diffusion increases considerably because the diffusion coefficient increases by a factor of $10^{4}$ as soon as the soil becomes unsaturated and methane concentrations are still high in the uppermost layers. After a period of about 15 days, emission by diffusion declines again owing to oxidation in the unsaturated zone. Moore and Roulet [1993] observed a similar pattern: increased fluxes with falling water table to $20 \mathrm{~cm}$ depth within 10 days, followed by decreased fluxes as the water table continues to fall further.

Figure 3 shows a comparison between simulated and observed methane concentration profiles for the period between January 1992 and January 1993. The observations and model results show the same seasonal pattern: higher methane concentrations in the winter and spring and decreased methane concentrations in the summer and autumn. The reason for this is that during the growing season a large fraction of methane is removed from the soil by plants. However, in the model, removal of methane from the soil by plants seems to start too early (May 16 and June 4 ). This probably happens because in the model the time plants need to develop is underestimated. At the beginning of the winter, the concentrations increase faster in the data than in the model (November 14, December 13, and January 9) again because the simulation of the seasonal variation of the growing stage of the plants seems to fail in late autumn. However, these discrepancies occur only at times when the production rate is relatively low and thus affect simulated methane emissions only slightly.

\subsection{Site 2: Minnesota}

Figure 4 shows the results of a model-data comparison performed at site 2 with data from Dise [1993]. As in section 3.1, in the lower part, the observed forcing data which are the position of the water table (Figure 4b) and the soil temperature (Figure 4c) are plotted. In Figure 4a the comparison between observed and simulated methane emissions is shown. Here the agreement seems to be not as good as at site 1 which can be partly explained by the fact that at site 1 the model results are compared to an average of three measurements, which clearly differ from each other at some times (see \pm 1 standard deviation error bars in Figure 2a), whereas at site 2 only one chamber was used. In addition to that, other factors affecting methane production and emission such as the chemical conditions in the soil, which are not considered in the model (see above), could be important at some times. Generally, simulated methane emissions respond in a similar way to changes in the soil temperature and the position of the water table as at site 1. Further tests of the model conducted at four other microsites within this wetland where vegetation and soil temperatures were similar, but the position of the water table is in one case much lower ( -40 to $-50 \mathrm{~cm}$ belowground) yield similar results [Walter, 1998].

\subsection{Site 3: Finland}

In Figure 5 the results of a comparison between modeled and observed methane emissions from two microsites (flark (minerotrophic hollow) and low hummock) of a Finnish wetland
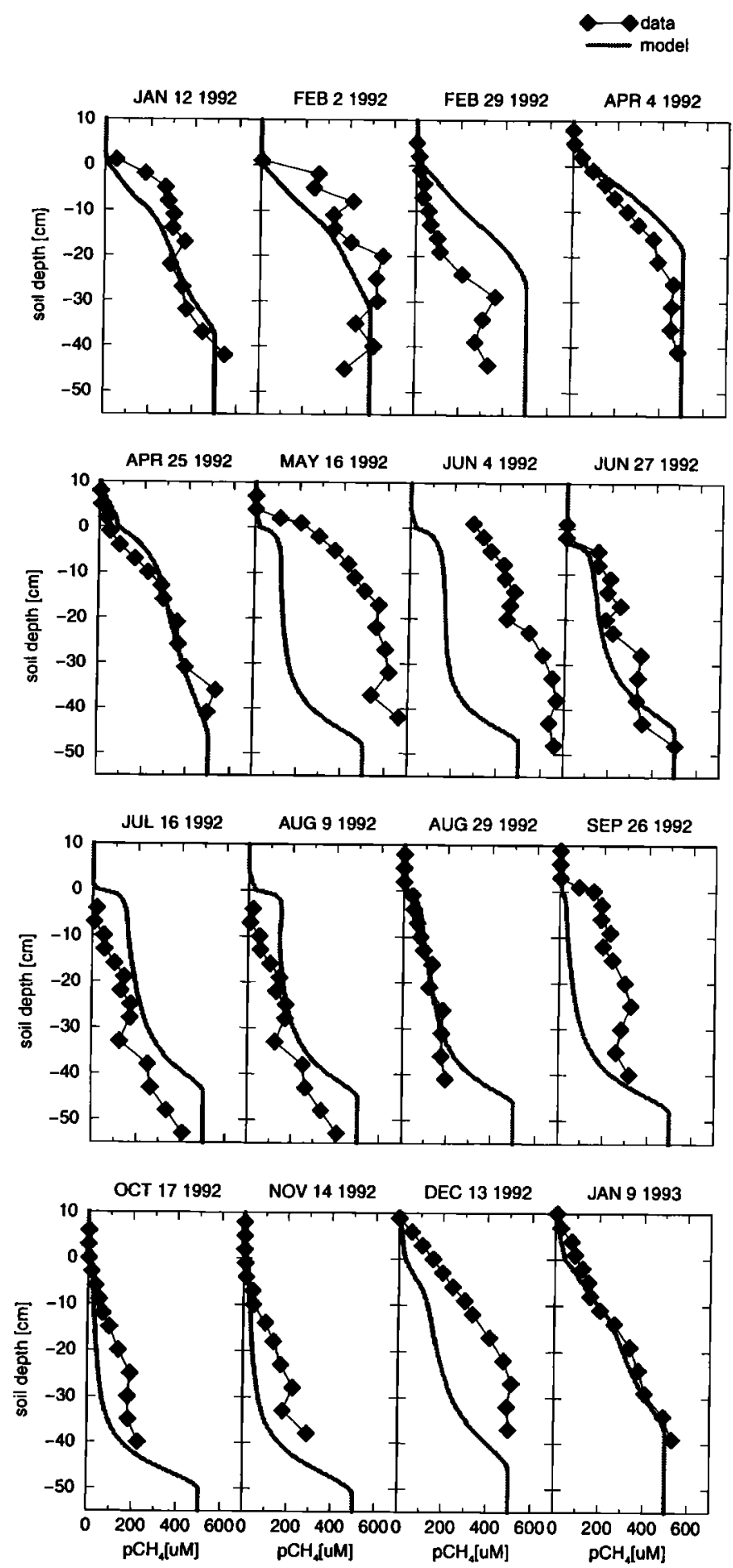

Figure 3. For site 1, comparison between modeled (thick line) and observed (squares) methane concentrations in the soil (observational data from Shannon and White [1994]).

[Saarnio et al., 1997] are shown. We focus on intrasite variations within the same wetland based on differences in the position of the water table. The same values for $\mathbf{R}_{\mathbf{0}}, \mathbf{V}_{\text {max }}$, nsoil, nroot, and $T_{\text {veg }}$ [Alm et al., [1997] for description of vegetation] are used at the two microsites. In addition, the soil temperatures as shown in Fig- 

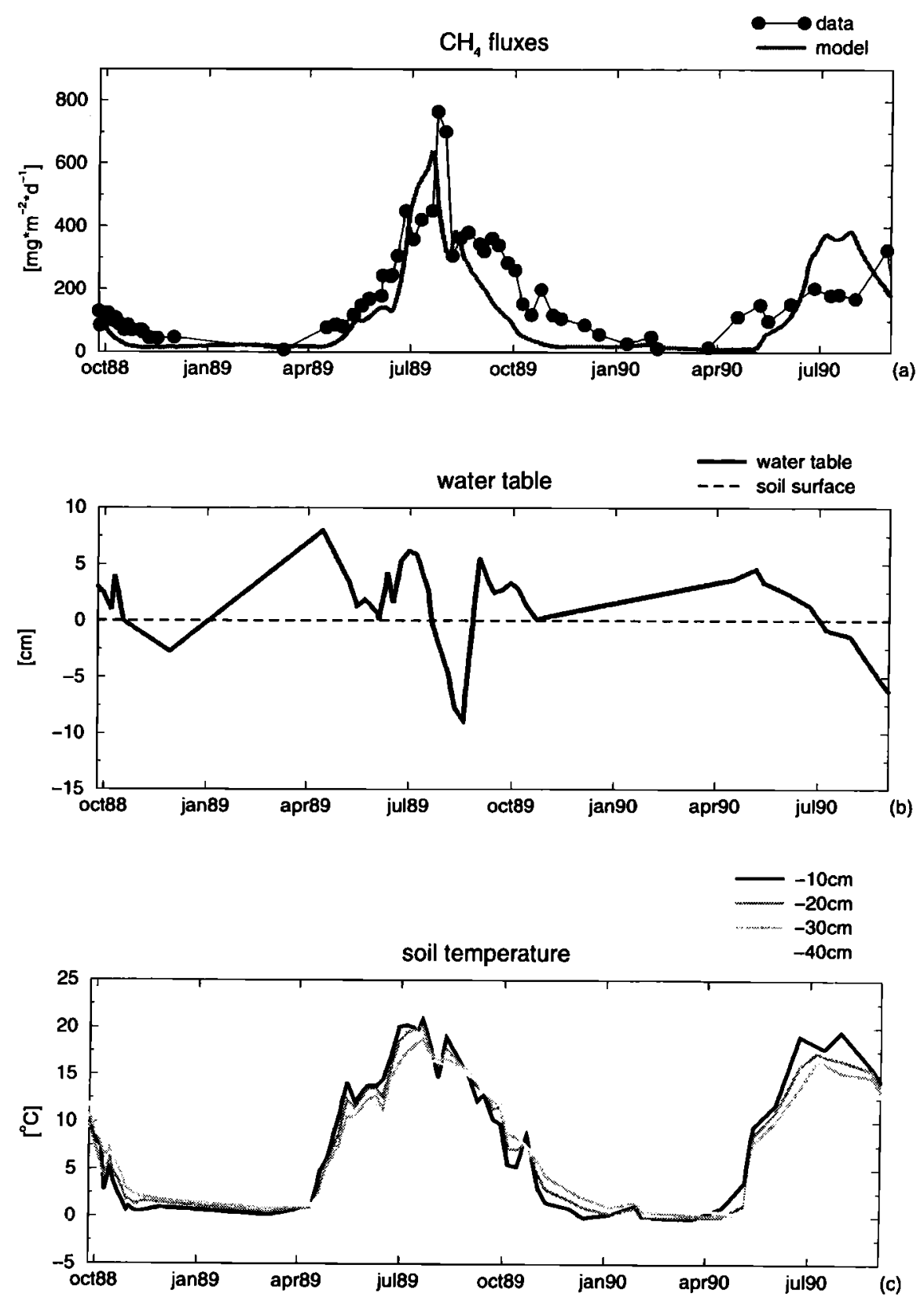

Figure 4. For site 2, (a) comparison between modeled (thick line) and measured (dots) methane emissions; (b) forcing, observed position of the water table; and (c) forcing, observed soil temperature at different soil depths (observational data from Dise [1993]).

ure $5 \mathrm{c}$ are the same at both microsites. Hence the differences in simulated methane emissions between these two microsites are attributed to differences in the positions of the water table only. The low hummock is elevated by about $15 \mathrm{~cm}$ relative to the flark. Figure 5b shows the positions of the water table at the low hummock and the flark. The modeled and observed methane emissions from these two microsites are plotted in Figure 5a (the grey areas are averages of the fluxes from all the collars of the two microsites \pm 1 standard deviation). The methane emissions from the flark are considerably higher than those from the low hummock because there is less oxidation due to the higher water table level at the flark site. This effect can be seen both in the observations and the model results. At the flark, simulated methane emissions begin too early (Figure 5a). The modeled fluxes follow directly the changes in the soil temperature (Figure $5 \mathrm{c}$ ) whereas in the observations there is a time lag between the soil temperature and methane emissions. The reason for this time lag could be that before methane production can start, appropriate soil conditions for methanogenesis must be established and suitable substrate for methanogenesis must be produced. This is not taken into account in the model. Another reason could be that at these microsites, the deeper soil layers contribute more to methane production than the upper ones, possibly owing to better substrate availability and/or quality. This would cause modeled methane emissions to follow the soil tem- 

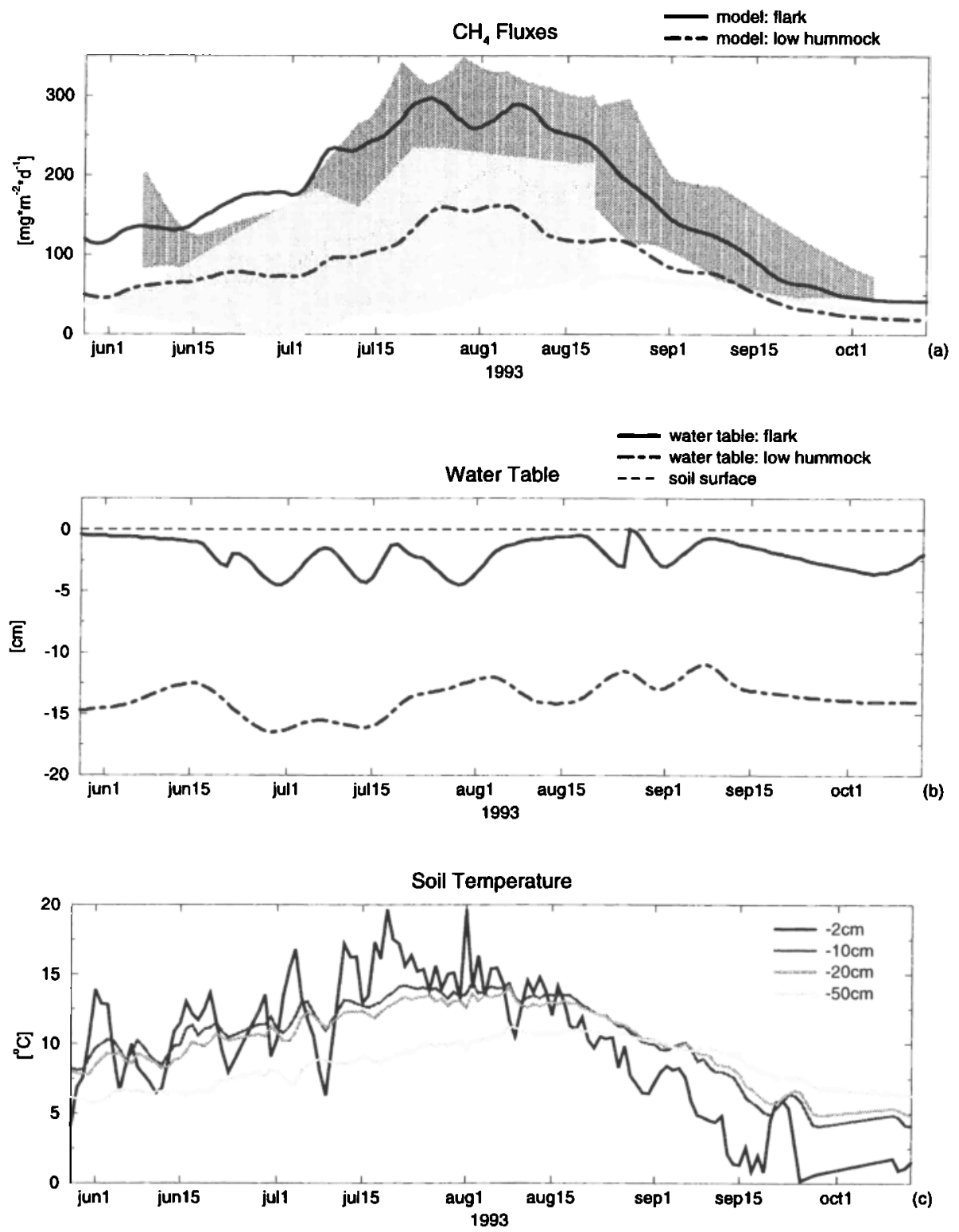

Figure 5. For site 3, comparison of methane emissions from two microsites. (a) Modeled fluxes from the flark (solid line) and the low hummock (dot-dashed line); the shaded areas are the areas between the average of all measurements from the respective microsite $+/-1$ standard deviation, flark (dark grey) and low hummock (light grey). (b) Forcing, observed positions of the water table at the flark (solid line) and the low hummock (dot-dashed line) relative to the soil surface (dashed line). (c) Forcing, observed soil temperature at different soil depths (the same at both microsites) (observational data from Saarnio et al. [1997]).

perature of deeper soil layers which lags behind the temperature of the upper soil layers. This effect, however, is only seen at the two microsites of the Finnish wetland. The model is also tested at two further sites within this wetland with similar water table patterns and vegetation (one site has a deeper rooting depth) [Walter, 1998]. The results obtained there are similar to the ones presented here

\subsection{Site 4: Alaska}

A further test is performed with data from an Alaskan Arctic tundra site which is underlain by permafrost [Whalen and Reeburgh, 1992] In Figures $6 \mathrm{~b}$ and $6 \mathrm{c}$ the observed forcing data water table, thaw depth, and soil temperature are plotted. Since the three chamber measurements at the black hole microsites (called BH13) differ much, we plot the obtained fluxes from each chamber as well as the average of these measurements to compare them with the simulated fluxes (Figure 6a). The vegetation consists of $S p h$ agnum mosses, and there are no vascular plants which means that plant-mediated transport does not occur and hence $T_{\text {veg }}=0$ (Table 2). During the summer the soil starts to thaw, and the maximum depth of thaw is about $60 \mathrm{~cm}$ belowground, attained in autumn An increasing thaw depth means that the production zone is being enlarged with time. Therefore simulated methane emissions are of the same magnitude in September as in August even though both the soll temperature and the water table levels are lower in Sep- 

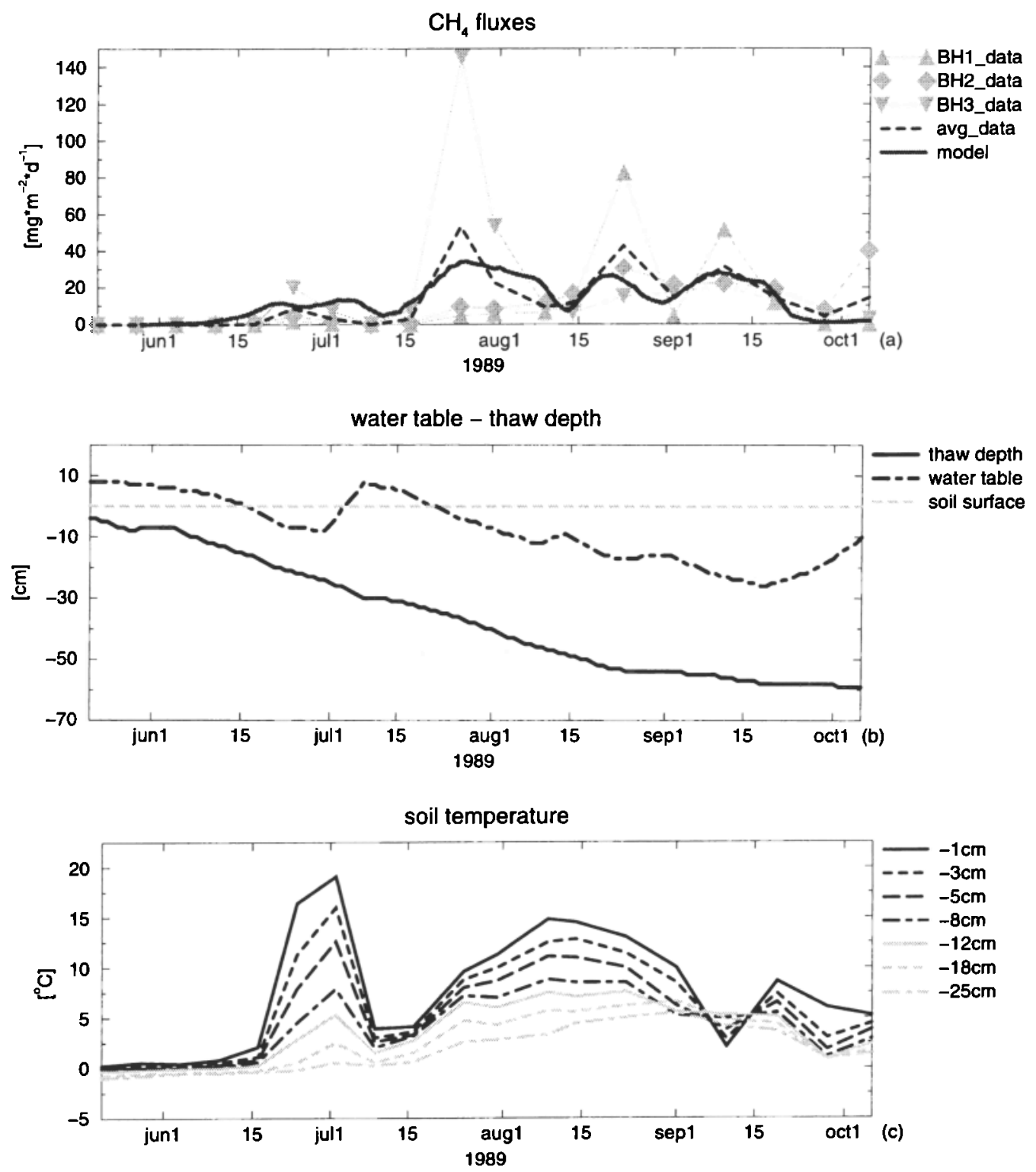

Figure 6. For site 4, comparison between modeled (thick line) and measured (the triangles and the square are observations from three stations within the "Black Holes" site, the dashed line marks the average of those three measurements) methane emissions. (b) Forcing, observed thaw depth (soild line) and water table (dot-dashed line). (c) Forcing, observed soil temperature at different soil depths (observational data from Whalen and Reeburgh [1992]).

tember. Here $V_{\max }$, which describes the maximum methane oxidatIon rate in the unsaturated soil zone, has been set to only $3 \mu \mathrm{M}$ $h^{-1}$ as opposed to values of $20 \mu \mathrm{M} \mathrm{h}^{-1}$ at most other sites (Table 2) Because of that low $V_{\max }$ value, the effect of a declining water table on methane emission is smaller than at the Finnish wetland ste discussed in section 3.3. One could speculate what the reason for this low $V_{\max }$ value might be. For example, the oxidation potential of the methanotrophic bacteria could be lower at that site, or the soil moisture content in the soil layers above the water table could be higher (the soil moisture in the unsaturated zone is not taken into account in the model). However, the $\mathrm{V}_{\max }$ value chosen here is still close to observed values for $V_{\max }$ lying in the range between 5 and $50 \mu \mathrm{M} \mathrm{h}^{-1}$ [Dunfield et al, 1993; Knoblauch, 1994, Krumholz et al, 1995, Moore and Dalva, 1997, Sundh et al., 1994; Watson et al., 1997]. Data from two other microsites of this wetland are used to test the model [Walter, 1998]. There agaun three chambers were used at each microsite, and soil temperature and thaw depth show a similar behavior as at the microsite shown here. However, water table levels go down to $-40 \mathrm{~cm}$, and one microsite is vegetated. Again, the results from the three chambers differ considerably and agreement between simulated and observed methane emissions is worse than at the other test sites.

\subsection{Site 5: Panama}

As a last example, a test against data from a tropical wetland in Central Panama [Keller, 1990] is discussed At this site, methane emissions were measured, but nether the soil temperature nor the 

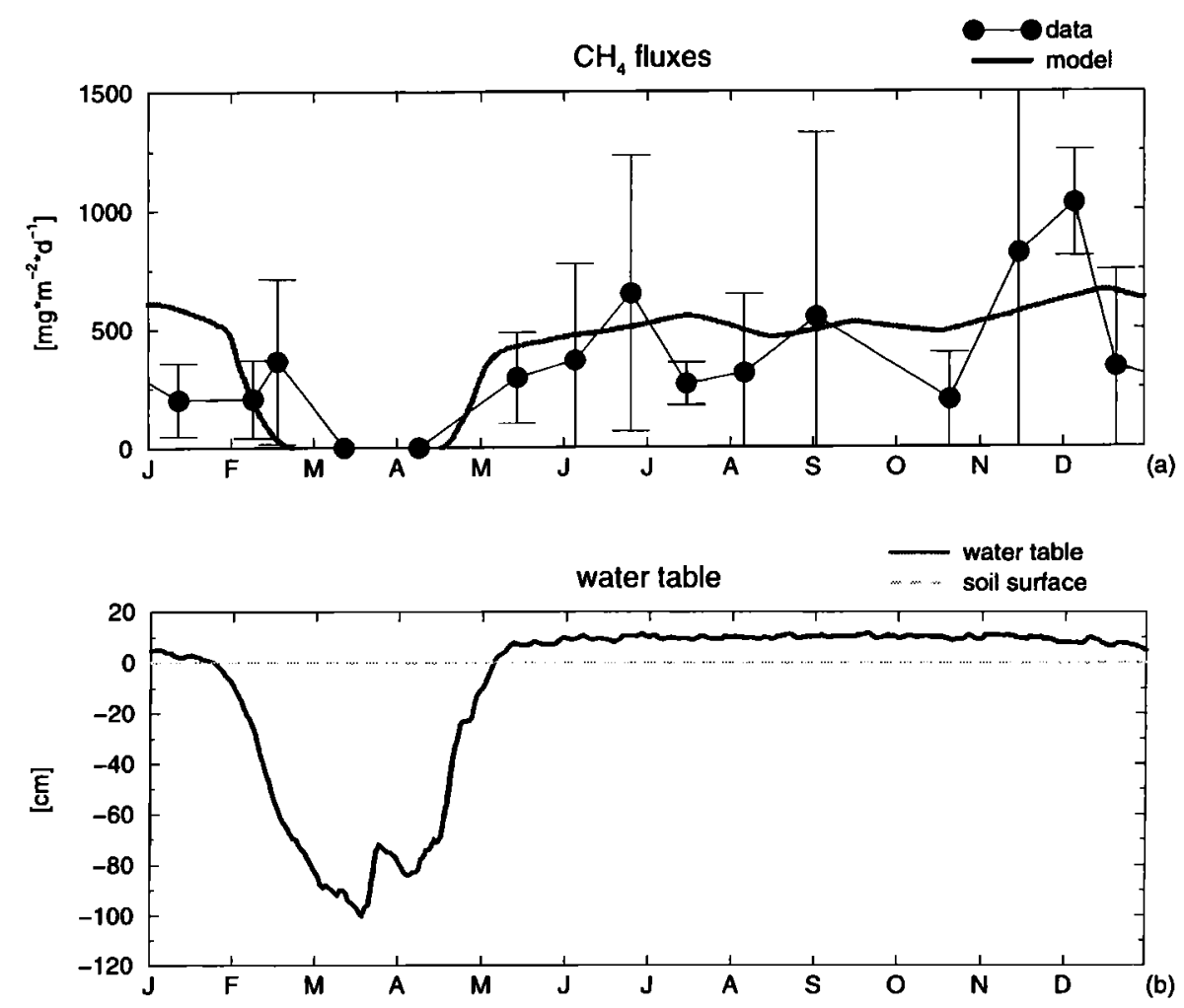

Figure 7. For site 5, (a) comparison between modeled (thick line) and measured (dots with $+/-1$ standard deviation error bars) methane emissions and (b) forcing, position of the water table relative to the soil surface as calculated with the hydrologic model forced by the ECHAM4 model (see text) (observational data from Keller [1990]).

water table was observed. This site is characterized by a 4-month dry season between February and May. According to M. Keller (personal communication, 1997), the water table rarely exceeded $+30 \mathrm{~cm}$ during the wet season and was below $50 \mathrm{~cm}$ below ground during the dry season, and the soil temperature was nearly constant over the whole year. In order to obtain input data for the methane model for this test, the output of a climatological run of the ECHAM4 model [Roeckner et al., 1996] in T106 (T106-truncation corresponds to $1.1^{\circ}$ by $1.1^{\circ}$ ) is used. The soil temperature at different soil depths is calculated by the ECHAM4 model, and the water table levels are calculated by a hydrologic model [Walter, 1998] driven by climate data from the same run of the ECHAM4 model. Since the necessary model parameters (Table 2) are not known for this site the values from global data sets of these parameters which have been established for a global application of the methane model [Walter, 1998] are used. In Figure 7b the water table calculated by the hydrologic model forced by the ECHAM4 model is plotted. The soil temperature is almost constant throughout the year (not shown). This is consistent with the information by M. Keller (personal communication, 1997) (see above). Figure 7 a shows the comparison between the simulated and the observed methane emissions. The latter are averages of seven stations plotted with \pm 1 standard deviation error bars. The most striking point is that the modeled as well as the observed methane emissions are zero or even negative during the dry season, attributable to the decline of the water table to depths of about $80-100 \mathrm{~cm}$ belowground, causing the development of a large oxic zone where methane is consumed. This data set is the only tropical data set where methane emissions were measured over a period of at least one season that has been available to us until now. Since it is possible that in tropical wetlands processes are dominant which are not yet included in the model, additional data sets from tropical wetlands are needed, in order to further improve and test the model. This is particulary important because tropical wetlands are a very large methane source [e.g., Hein et al., 1997].

\subsection{Relationship Between Climate Input and Methane Emissions}

The time series used above to test the model show that the pattern of methane emissions at most high-latitude sites (1-3) is mainly controlled by soil temperature as long as the water table is above the soil surface. If the water table is below the soil surface and does not vary much, like at site 3 (Figure 5, hummock), the pattern of methane emissions is again mainly driven by changes in soil temperature, but the amplitude is influenced by the water table depth. However, as soon as the water table fluctuates around the soil surface, as for example at site 1 , this connection between soil temperature and methane flux no longer applies. As it is shown in Figure 2 and discussed in section 3.1, methane emissions increase in the first about 15 days after a fall of the water table below the soil surface. This behavior is also reflected in Figure 8 which shows the connection between simulated methane emissions and soil temperature and water table at site 1 . Figure 8 shows that there is a positive connection between soil temperature and simulated methane emissions. However, in the temperature range 


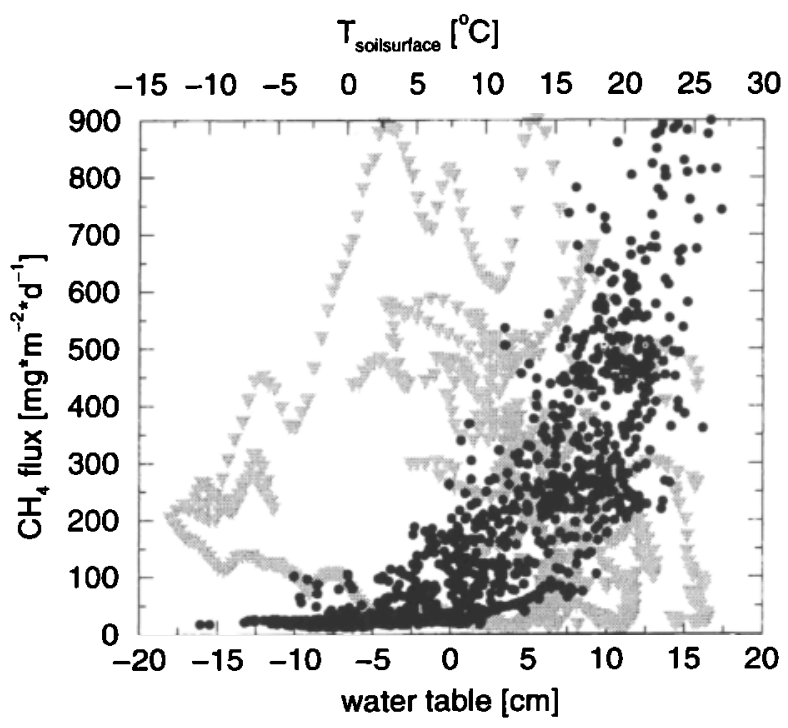

Figure 8. For site 1, the relationship between input data and simulated $\mathrm{CH}_{4}$ emissions and the connection between the soil temperature $T_{\text {soil }}$ at the soil surface (black dots) and the position of the water table (grey triangles) and simulated $\mathrm{CH}_{4}$ emissions.

between $15^{\circ}$ and $20^{\circ} \mathrm{C}$, for example, simulated methane emissions range between 50 and $900 \mathrm{mg} \mathrm{m}^{-2} \mathrm{~d}^{-1}$. Figure 8 also shows that there is no connection between water table and simulated methane emissions at site 1 . The highest methane emissions occur when the water table is $5 \mathrm{~cm}$ above or $5 \mathrm{~cm}$ below the soil surface. When the water table is 13 or $17 \mathrm{~cm}$ belowground, methane fluxes can be as high as 450 and $250 \mathrm{mg} \mathrm{m}^{-2} \mathrm{~d}^{-1}$, respectively. This agrees well with the results of Shannon and White [1994] who calculated the correlation between soil temperature and water table and observed methane fluxes at that site. At the Arctic tundra site (site 4) the connection between the environmental parameters soil temperature, water table and thaw depth, and simulated methane emissions looks different (Figure 9). There is no obvious connection between soll temperature and simulated methane emissions (F1gure 9a), and the same applies to the connection between water table depth and simulated methane emissions (Figure 9b). However, simulated methane fluxes are higher at lower thaw depths (Figure 9b), i.e., when a larger part of the soil is thawed. Whalen and Reeburgh [1992] found that methane emissions from all stations investigated at that Arctic tundra site correlated best with "centimeter-degrees," being defined as the absolute value of the product of thaw depth and mean soil temperature to permafrost. At the tropical test site (site 5) the temperature does not vary much, and from Figure 7 it is clear that there is a connection between the position of the water table and simulated methane emissions. These results show that in most cases, simple relationships between environmental parameters and methane fluxes do not even apply at one particular site. They differ from site to site and hence a relationship between climate input and methane emissions found at one site cannot be applied to other sites and other conditions. This means that if one wants to model methane emissions from different wetlands and under varying environmental conditions, a more process-based approach is needed.

\section{Sensitivity Tests}

\subsection{Sensitivity to Model Parameters}

The sensitivity of the model to the choice of the parameters listed in Table 2 is tested at site 1 . The only other site-specific model parameter not listed in Table 2 is the relative volume of coarse pores $f_{\text {coarse, }}$ which has been set to 0.5 at all sites except site 5 , where it has been derived from a global data set used for the global model run as discussed by Walter [1998]. This data set gives a $f_{\text {coarse }}$ value of 0.22 for the tropical site 5 and also $f_{\text {coarse }}$ values around 0.5 for the regions where sites $1-4$ are located The model is only sensitive to the choice of $f_{\text {coarse }}$ at sites where diffusion is the dominant transport mechanism. This is only the case at site 4, which is unvegetated and where the water table is below the soil surface most of the time. A sensitivity test carried out at site 4 shows that a change in $f_{\text {coarse }}$ of $+0.1 /-0.1$ leads to a $125 \%$
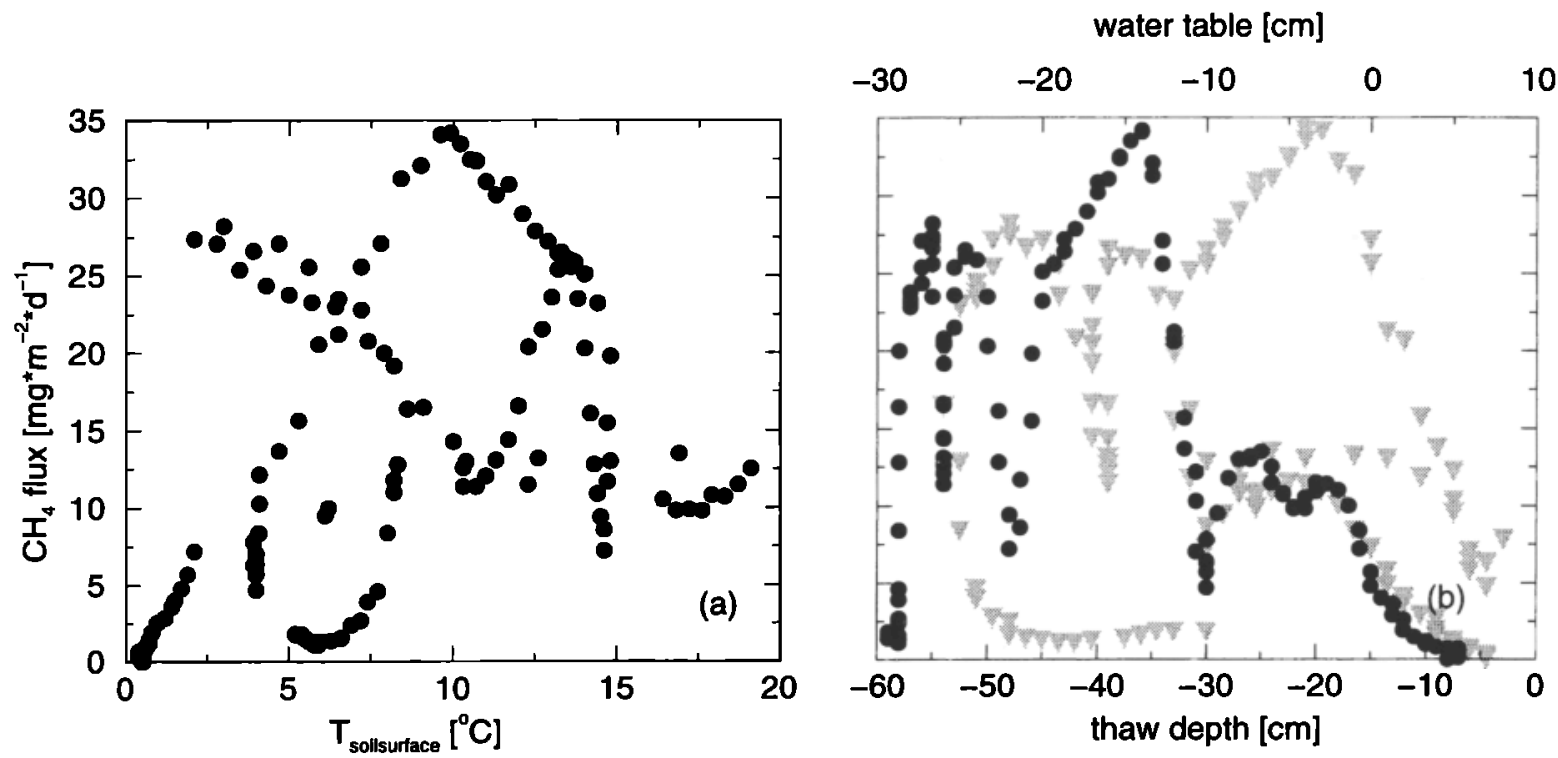

Figure 9. For site 4, the relationship between input data and simulated $\mathrm{CH}_{4}$ emissions. (a) Connection between the soil temperature $\mathrm{T}_{\text {soll }}$ at the soil surface and simulated $\mathrm{CH}_{4}$ emissions (b) Connection between the position of the water table (grey triangles) and the thaw depth (black dots) and simulated $\mathrm{CH}_{4}$ emissions 

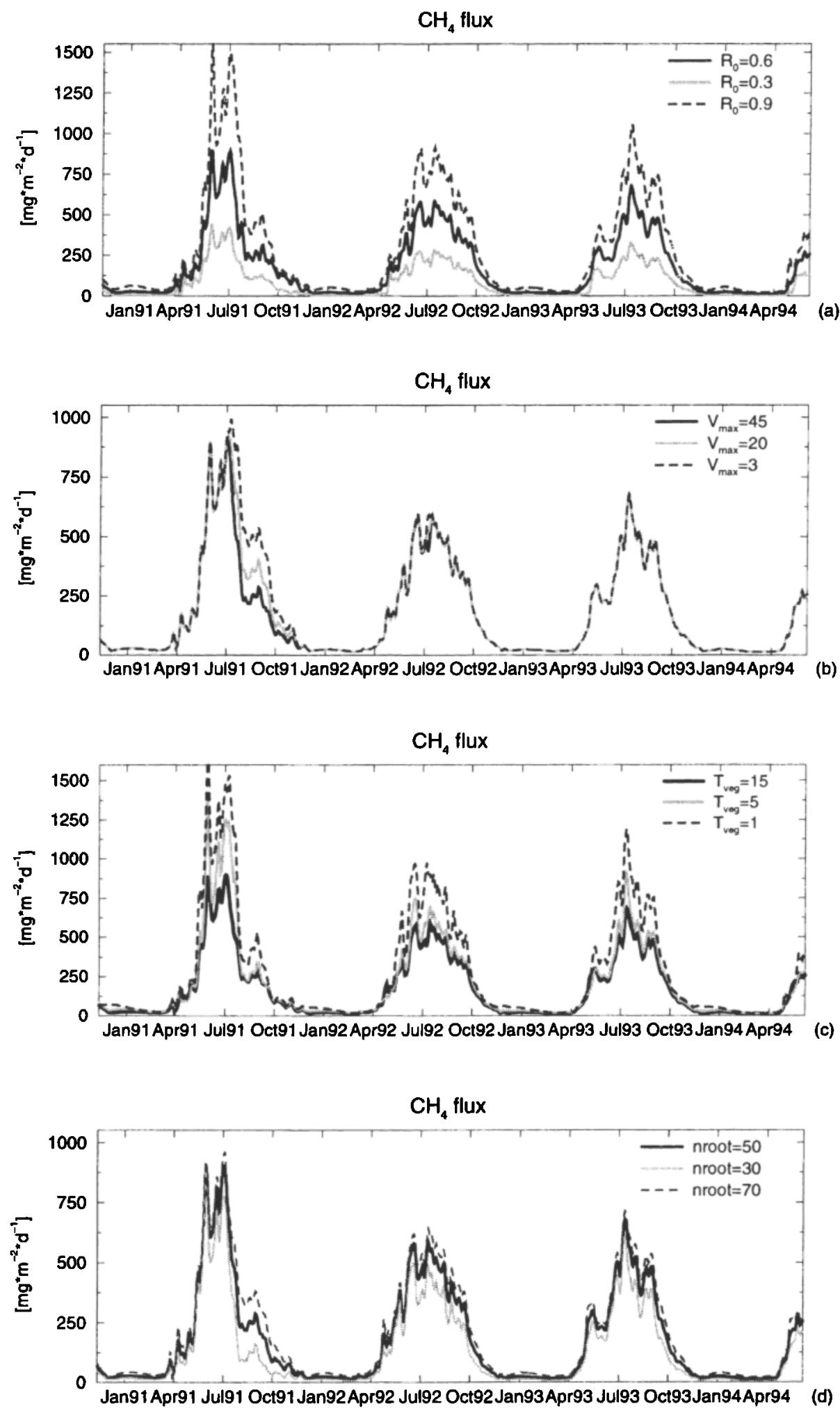

Figure 10. Sensitivity to $\mathrm{R}_{0}, \mathrm{~V}_{\max }, \mathrm{T}_{\mathrm{veg}}$, and nroot tested at site1. (a) Simulated $\mathrm{CH}_{4}$ emissions using three different values for $\mathrm{R}_{0}$, namely 0.6 (soild line), 0.3 (grey line) and 0.9 (dashed line). (b) Simulated $\mathrm{CH}_{4}$ emissions using three different values for $V_{\max }$, namely $45 \mu \mathrm{M} \mathrm{h}^{-1}$ (soild line), $20 \mu \mathrm{M} \mathrm{h}^{-1}$ (grey line), and $3 \mu \mathrm{M} \mathrm{h}^{-1}$ (dashed line). (c) Simulated $\mathrm{CH}_{4}$ emissions using three different values for $\mathrm{T}_{\text {veg }}$, namely 15 (solid line), 5 (grey line), and 1 (dashed line). (d) Simulated $\mathrm{CH}_{4}$ emissions using three different values for nroot, namely $50 \mathrm{~cm}$ (solid line), $30 \mathrm{~cm}$ (grey line) and $70 \mathrm{~cm}$ (dashed line) 
increase/decrease in simulated methane emissions at that site (not shown). Differences in the soil depth nsoil only rarely affect simulated methane emissions (provided nsoil<nroot; not shown) because below the rooting depth the availability of substrate for methane production decreases exponentially (Equation (3)). In Figure 10 the results of the sensitivity tests with $R_{0}, V_{\text {max }}, T_{\text {veg, }}$, and nroot are shown. The results of the test with $R_{0}$ (Equation (5)), which is adjusted to each data set, show that $\mathbf{R}_{\mathbf{0}}$ influences the amplitude of simulated methane emissions but not the pattern (Figure 10a). The choice of the parameter $V_{\max }$ changes the model results only in situations when the water table is below the soll surface (Figure 10b). In this situation a lower $\mathrm{V}_{\max }$ leads to higher methane emissions because of lower methane oxidation rates (Equation (6)). The parameter $T_{\text {veg }}$ influences not only the fraction of methane which is transported through plants but also the amount of methane that is oxidized in the rhizosphere (Equation (14)). Its influence on simulated methane emissions depends on the water table level. If the water table is above the soil surface, a higher $T_{\text {veg leads to lower methane emissions (Figure 10c) }}$ because, in this case, less methane is transported by ebullition and more through plants. Therefore more methane is oxidized in the rhizosphere. This agrees well with observations by HolzapfelPschom et al. [1986] who found that there was more ebullition at unvegetated sites than at vegetated ones and that a larger fraction of produced methane was emitted from unvegetated sites, if the water table was above the soil surface. If the water table is below the soil surface, diffusion is high in the first month after the fall of the water table below the soil surface (Figure $2 b$ ). Since a lower $\mathrm{T}_{\mathrm{veg}}$ leads to higher diffusion rates because less methane is removed from the soil in this case (Figure 11), a lower $T_{\text {veg }}$ leads to higher methane emissions in the first month after the water table fell below the soil surface. In situations where the water table is below the soil surface for a longer period of time, a higher $T_{\text {veg }}$ leads to higher methane emissions because then a huge fraction of methane diffusing through the oxic soil layer is oxidized and methane transported through plants bypasses this oxic layer [Walter, 1998]. In Figure 11 the effect of $T_{\text {veg }}$ on the simulated soll methane concentration is shown. It is clear that higher $T_{\text {veg }}$ values lead to lower soil methane concentrations because more methane is removed from the soil by plants. This agrees well with observations that the soil methane concentration is higher at unvegetated sites than at vegetated sites [Chanton and Dacey, 1991]. The rooting depth nroot is the soil depth down to which plants can extract methane from the soil (Equation (16)). Furthermore, nroot affects the vertical distribution of substrate in the soil (Equation (3)). Throughout the root zone, substrate availability is constant, then it decreases exponentially. In the model the combined effect of an enlarged production zone and more plant-mediated transport and hence more rhizospheric oxidation is almost balanced, if the water table is above the soil surface (Figure 10d). However, if the water table falls below the soil surface transformIng the soil above the water table from a production into a consumption zone, the enlargement of the zone with high productivity (higher nroot) shows a pronounced effect on simulated methane emissions.

\subsection{Sensitivity to Changes in the Input Data (Climate Forcing)}

The effect of changes in the soil temperature and water table on simulated methane emissions is shown in Figure 12. The effect of the water table being raised or lowered by $10 \mathrm{~cm}$ (F1gure $12 \mathrm{~b}$ ) on simulated methane emissions is plotted in Figure 12a As long as
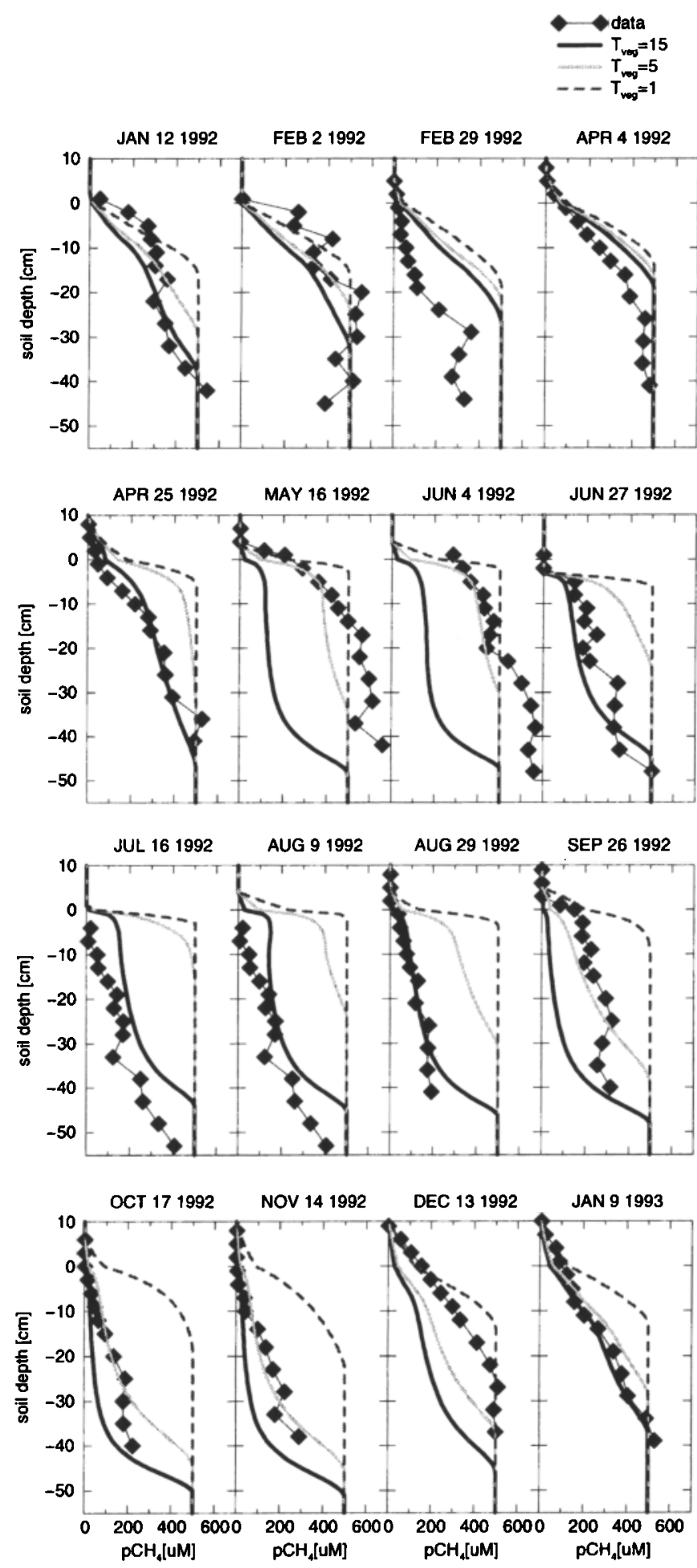

Figure 11. Sensitivity to $\mathrm{T}_{\text {veg }}$ tested at site 1 . Simulated $\mathrm{CH}_{4}$ concentration profiles in the soil using three different values for $\mathrm{T}_{\mathrm{veg}}$, namely $T_{\text {veg }}=15$ (solid lines), $T_{v e g}=5$ (grey lines), and $T_{\text {veg }}=1$ (dashed lines) and comparison with observations (squares).

the water table is above the soil surface, the height of the water table does not change simulated methane emissions If the water table is below the soil surface, methane emissions decrease with decreasing water table Therefore the effect of a climatic change 

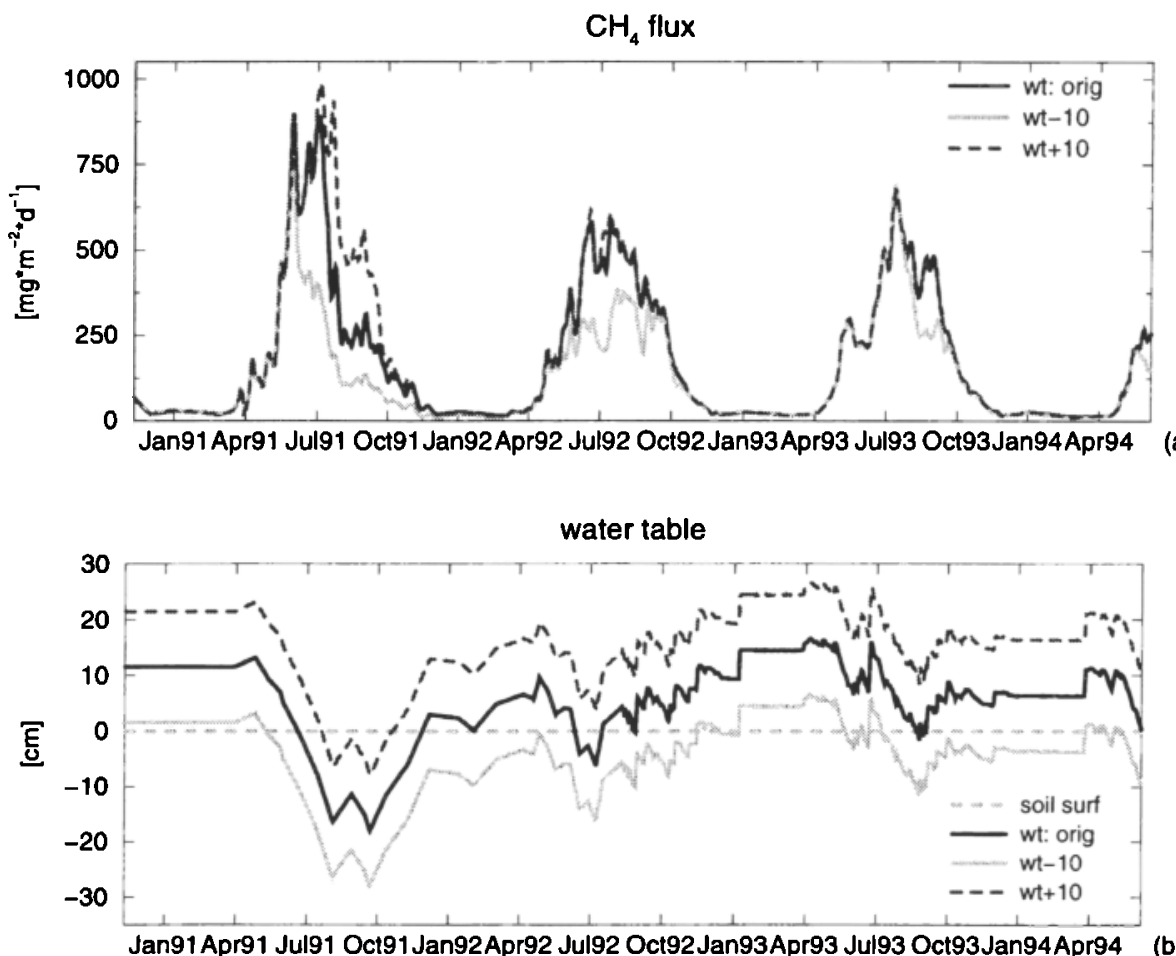

(a)

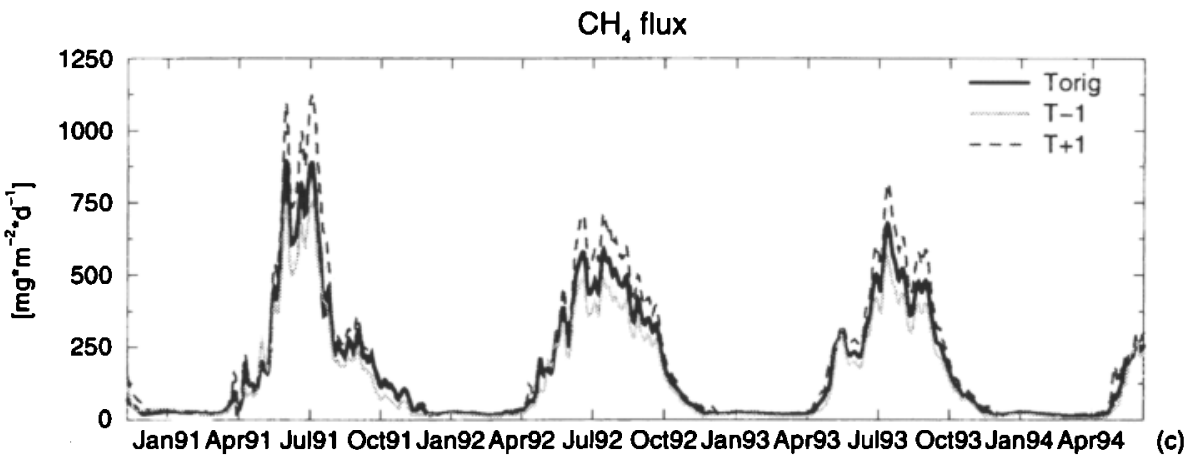

Figure 12. Sensitivity to forcing data for (a and b) water table and (c) soil temperature tested at site 1. (a) Simulated $\mathrm{CH}_{4}$ emissions using the original water table (solid line), a by $10 \mathrm{~cm}$ lowered water table (grey line), and by $10 \mathrm{~cm}$ raised water table (dashed line). (b) Forcing, different water table levels relative to the soil surface (grey, dashed line) used to test the sensitivity of the model to the water table. Original water table (black, solid line), by $10 \mathrm{~cm}$ lowered water table (grey, soild line), by $10 \mathrm{~cm}$ raised water table (black, dashed line). (c) Simulated $\mathrm{CH}_{4}$ emissions using the original soil temperature (solid line), by $1^{\circ} \mathrm{C}$ lowered water table (grey line) and by $1^{\circ}$ raised water table (dashed line).

leading to a shift in the position of the water table at a given site depends on the conditions prevailing at that site. If the site is relatıvely dry like in 1991, a shift in the position of the water table is very pronounced (Table 3 ), whereas if the site is relatively wet as in 1993, the same shift in the water table changes methane emissions much less. A uniform change in the soil temperature by $\pm 1^{\circ} \mathrm{C}$ leads to a regular shift in the amplitude of simulated methane emissions which does not depend on the position of the water table (Figure 12c). In summer, when soil temperature is higher, absolute changes in simulated methane emissions due to $\pm 1^{\circ} \mathrm{C}$ change in soil temperature are larger than in winter (see also Figure 8) $\mathrm{A}$ uniform increase in the soil temperature of $1^{\circ} \mathrm{C}$ leads to an increase in simulated methane emissions of about $21 \%$ at that site in all 3 years (Table 3 ), whereas a uniform decrease in the soil temperature of $1^{\circ} \mathrm{C}$ reduces methane emissions by about $17 \%$ Sensitivity tests with a $\pm 1^{\circ} \mathrm{C}$ change performed at sites $2-5$ y1eld similar results (not shown). In all cases a $\pm 1{ }^{\circ} \mathrm{C}$ soil temperature change leads to a regular shift in the amplitude of simulated methane emissions, which increase by $19-23 \%$ if the soil temperature is $1^{\circ} \mathrm{C}$ higher and decrease by $17-21 \%$ if the soil temperature is $1^{\circ} \mathrm{C}$ lower. Thus $\mathrm{a} \pm 1^{\circ} \mathrm{C}$ change in the soil temperature leads to a change of the order of $\pm 20 \%$ in simulated methane emissions, independent of the environmental conditions prevailing in the wetland. Further sensitivity tests conducted at site 1 but using a by 10 or $20 \mathrm{~cm}$ lower water table and in one case also a $T_{\text {veg }}$ of 0 (no vegetation/plant-mediated transport) show similar results. Changes in temperature mainly affect methane production and oxidation rates (Equations (5) and (6)) Methane production 
Table 3. Sensitivity of Simulated $\mathrm{CH}_{4}$ Fluxes to Climate Forcing

\begin{tabular}{cccc}
\hline Run & 1991 & 1992 & 1993 \\
\hline $\mathrm{T}+1^{\circ} \mathrm{C}$ & $+20.5 \%$ & $+20.7 \%$ & $+20.5 \%$ \\
$\mathrm{~T}-1^{\circ} \mathrm{C}$ & $-16.6 \%$ & $-17.0 \%$ & $-17.1 \%$ \\
$\mathrm{wt}+10 \mathrm{~cm}$ & $+25.3 \%$ & $+1.4 \%$ & $0.0 \%$ \\
$\mathrm{wt}-10 \mathrm{~cm}$ & $-36.6 \%$ & $-20.6 \%$ & $-10.8 \%$ \\
control & $78.2 \mathrm{~g} \mathrm{~m}^{-2} \mathrm{yr}^{-1}$ & $70.4 \mathrm{~g} \mathrm{~m}^{-2} \mathrm{yr}^{-1}$ & $65.5 \mathrm{~g} \mathrm{~m}^{-2} \mathrm{yr}^{-1}$ \\
\hline
\end{tabular}

Results of the sensitivity tests to the input data at site 1 . In runs $\mathrm{T}+1^{\circ} \mathrm{C} /$ $\mathrm{T}-1^{\circ} \mathrm{C}$ the soil temperature was uniformly increased/decreased by $1^{\circ} \mathrm{C}$ in all soil layers throughout the whole simulation period (rows 1 and 2). In runs $w t+10 \mathrm{~cm} / w \mathrm{wt}-10 \mathrm{~cm}$ the position of the water table was uniformly increased/decreased by $10 \mathrm{~cm}$ throughout the whole simulation period (see Figure 12) (rows 3 and 4). Simulated annual methane emissions for the years 1991-1993 $\left(\mathrm{g} \mathrm{CH}_{4} \mathrm{~m}^{-2} \mathrm{yr}^{-1}\right)$ (row 5).

depends much stronger on temperature $\left(Q_{10}=6\right)$ than methane oxidation $\left(Q_{10}=2\right)$, which explains why this result is obtained at all sites. The same sensitivity test (a $\pm 1^{\circ} \mathrm{C}$ soil temperature change) performed with this model on a global scale shows the same result [Walter, 1998]. However, it is worth noting that the effect of temperature changes on the position of the water table (through evapotranspiration) is not considered in this sensitivity test. In addition, climatic changes always have irregular spatial and temporal patterns in more than one climate variable. In order to predict changes in methane emissions from natural wetlands due to climatic changes on longer timescales, it will be necessary to consider also the effects of changes in other factors such as vegetation, NPP, and the global wetland distribution. However, these sensitivity studies demonstrate that methane emissions from natural wetlands could considerably be affected by possible climatic changes in the future.

\section{Summary and Conclusion}

In this study we presented a model to simulate the processes leading to methane emission within a one-dimensional soil column as a function of climate. The model differs from all other models in the literature in the way that transport is parameterized. Two opposing processes operate in soil, namely methane production in the anoxic soil zone and methane consumption in the oxic soil zone. Therefore transport, which occurs by diffusion, ebullition, and through plants, plays an important role in determining the fraction of produced methane that is emitted into the atmosphere. Moreover, the different transport mechanisms influence the velocity at which methane is transported to the atmosphere. For climate forcing variables, soil temperature, water table, and thaw depth (which had been observed at four sites and were simulated at one site) as well as model derived NPP were used. Sitespecific model parameters are soil depth nsoil, rooting depth nroot, the relative volume of the coarse pores $f_{\text {coarse, }}$, the quality of plant-mediated transport $T_{\text {veg, }}$ and in some cases the maximum methane oxidation rate $\mathrm{V}_{\max }$. The chemical properties (including substrate availability and quality for methanogenesis) of the soil and their influence on methane production are not modeled explic- itly but are included in the parameter $\mathbf{R}_{\mathbf{0}}$ which has been adjusted to each data set. In order to apply the model to other sites without tuning $\mathbf{R}_{\mathbf{0}}$ or to larger (regional or global) scales, a method must be developed to derive $R_{0}$ from biogeochemical, biogeographical, and climatic variables. In the future a process-based model to simulate the production of substrate for methanogenesis as a function of the soil conditions and the climate could also be used to replace the tuning parameter $\mathbf{R}_{0}$. The occurrence of turbulent diffusion in the standing water and its effect on transport and reoxidation of methane could be important at tropical sites in particular. However, since the data sets used in this study showed no evidence that this process is of general importance, it has not been included in the model.

In this article results of tests of the model against observational data from five different wetland sites located in North America, northern Europe, and Central America, representing a large variety of environmental conditions, are presented. The observational periods range from one season to several years. One site is underlain by permafrost and undergoes a seasonal freeze thaw cycle, while one site is located in the tropics where there is a dry/wetseasonal cycle. At one site, simulated methane concentration profiles in the soil were compared with observed vertical concentration profiles which reflect the vertical distribution of methane production, methane oxidation, and removal of methane by the different transport mechanisms. Hence, methane concentration profiles constitute an additional constraint to the model. We investigated the climate-induced variations of simulated methane emissions at the test sites and conclude that this model can be applied to different wetlands under various conditions and can also be applied to the global scale. The relationship between the input data (soil temperature, water table, and thaw depth at the permafrost site) and simulated methane emissions was examined. Simple relationships between the input data and simulated methane emissions do not, in general, apply at single sites, and they differ from site to site. This means that a more process-based approach is needed in order to simulate climate-induced variations of methane emissions from different wetland sites. Sensitivity tests of the model to the choice of model parameters were performed. The tuning parameter $\mathbf{R}_{\mathbf{0}}$ (in the methane production rate equation) changes the amplitude but not the pattern of simulated methane emissions. The choice of the parameter $V_{\max }$ (in the methane oxidation rate equation) alters simulated methane emissions in situations when the water table is below the soil surface. The response to different choices of the parameter $T_{\text {veg }}$ (quality of plant-mediated transport) depends on if the water table is above or below the soil surface and in the latter case for how long. In addition, the sensitivity of the model to uniform changes in the input data (soil temperature and water table) was tested. The response of a uniform change in the soil temperature of $\pm 1^{\circ} \mathrm{C}$ is of the order of a $\pm 20 \%$ change in methane emissions, independent of the environmental conditions prevailing in the wetland. However, the response of the model to uniform changes in the water table of $\pm 10 \mathrm{~cm}$ depends highly on the prevailing hydrologic conditions in the soil. In a relatively dry year an increase in the water table of 10 cm can enhance simulated methane emissions by as much as $\mathbf{2 5 \%}$, whereas in a wet year, there can be no change at all. Similarly, a decrease in the water table of $10 \mathrm{~cm}$ affects simulated methane emissions much more in a relatively dry year (in this study $37 \%$ less methane is emitted) than in wetter years. These numbers suggest that possible climate change in the future could considerably 
affect methane emissions from natural wetlands. However, in order to assess the change in methane emissions due to future possible climate change, a more realistic scenario simulation should be carried out. It should use simulated future climate as input data and include possible substrate limitation, changes in wetland areas, and melting of permafrost. The latter is included in the model via the soil temperature, since the soil layers where the soil temperature is below $0^{\circ} \mathrm{C}$ are considered to be frozen.

Further studies and data sets are necessary to further improve the model and test it more thoroughly. For example, only one data set from tropical wetlands was available to us. Since tropical wetlands are a very important methane source, we propose that in the future emphasis should be placed on long-term studies of methane emissions from tropical wetlands. In addition, it would be advantageous to test the model with a data set consisting not only of time series of the input and output data of the model (as it was the case in this study) but also of quantities calculated in the model such as methane production rate, methane oxidation rate, and the fraction of methane transported by the different transport mechanisms. No such data set is currently available, and the development of such a data set is therefore a priority to enable a more thorough testing of this model.

\section{Appendix A: Calculation of $f_{\text {NPP }}(t)$}

The function $f_{N P P}(t)$ is derived from the variation of the NPP with time, NPP(t), as calculated by the Biosphere-Energy Transfer and Hydrology (BETHY) model [Knorr, 1997]. The BETHY model is a process-based model describing the water balance on vegetated surfaces and bare soils and the $\mathrm{CO}_{2}$ balance in vegetation and soils. It uses remote sensing data and calculates the NPP on a $0.5^{\circ}$ by $0.5^{\circ}$ grid with monthly time steps. The model output from the BETHY model is linearly interpolated to get daily $\operatorname{NPP}(t)$ values. $\operatorname{NPP}(t)$ is used as a measure for the variation of substrate availability with time. Since part of the substrate is degraded from organic matter incorporated into the soil from dying plants in autumn, we presume that in regions with a change between growing and nongrowing seasons, i.e., where the growing season lasts for 3-9 months, the substrate availability increases again in autumn. We define the duration of the growing season as the time span when the soil temperature at $50 \mathrm{~cm}$ depth belowground is above $5^{\circ} \mathrm{C}$.

In regions where the growing season is shorter than 3 months or longer than 9 months, $\mathrm{f}_{\mathrm{NPP}}(\mathrm{t})$ is

$$
\mathrm{f}_{N P P}(\mathrm{t})=\mathrm{NPP}(\mathrm{t}) \quad \text { at any time, }
$$

whereas in regions with a growing season lasting 3 to 9 months, $f_{N P P}(t)$ is obtained from

$$
\begin{aligned}
& \text { NPP(t) } \\
& f_{N P P}(t)=N P P_{\text {last }}+\frac{N P P_{\text {max }}-N P P_{\text {last }}}{0.5 t_{\text {nongrow }}} t \quad \text { 1.half non-grs } \\
& N P P_{\max }-\left(\frac{N P P_{\text {max }}-N P P_{\text {first }}}{0.5 t_{\text {nongrow }}} t\right) \text { 2.half non-grs }
\end{aligned}
$$

Here $t_{\text {nongrow }}$ is the duration of the nongrowing season in days and $N P P_{\text {last }}$ and $N P_{\text {first }}$ denote the NPP(t) values of the last and first day of the growing season, respectively, and grs stands for "growing season."

\section{Appendix B: Calculation of $\mathbf{f}_{\text {grow }}(t)$}

The function $f_{\text {grow }}(t)$ describing the growing state of the plants is assumed to be a function of the LAI and is calculated according to Dickinson et al. [1993]. We define a mean LAI depending on the daily mean temperature at $50 \mathrm{~cm}$ depth below ground $T_{50}=T(t, z=120 \mathrm{~cm})$ and hence calculate $\mathrm{f}_{\text {grow }}(\mathrm{t})$ from

$$
\begin{gathered}
\Lambda_{\text {min }} \\
\mathrm{f}_{\text {grow }}(\mathrm{t})=\Lambda_{\min }+\Lambda\left(1-\left(\frac{\mathrm{T}_{\text {mat }}-\mathrm{T}_{50}}{\mathrm{~T}_{\text {mat }}-\mathrm{T}_{\mathrm{gr}}}\right)^{2}\right) \mathrm{T}_{\mathrm{gr}} \\
\mathrm{T}_{\mathrm{gr}} \leq \mathrm{T}_{50} \leq \mathrm{T}_{\text {mat }} \\
\mathrm{T}_{\text {mat }}<\mathrm{T}_{50}
\end{gathered}
$$

where $\Lambda_{\min }$ and $\Lambda$ have been chosen to be 0 and 4 , respectively, and $\Lambda_{\max }=\Lambda_{\min }+\Lambda . T_{\mathrm{gr}}$ is the temperature at which plants start to grow. In regions where the annual mean soil temperature is below $5^{\circ} \mathrm{C}, \mathrm{T}_{\mathrm{gr}}$ has been set to $2^{\circ} \mathrm{C}$ and elsewhere to $7^{\circ} \mathrm{C}$. This distinction has been made because in cold regions plants start to grow at lower temperatures than in temperate and warm regions. The same is valid for the temperature at which they reach maturity, $T_{\text {mat }}$, which has been set to $\mathrm{T}_{\mathrm{mat}}=\mathrm{T}_{\mathrm{gr}}+10^{\circ} \mathrm{C}$.

Acknowledgments. The authors are very grateful to R. Shannon, J. White, N. Dise, S. Saarnio, W. Reeburgh, M. Keller, and D. Valentine for providing us with their data sets and further information on the sites and for very useful and interesting discussions. In addition, $B$. Walter would like to thank $P$. Frenzel for numerous informative discussions and also her colleagues at the Max-Panck-Institut für Meteorologie in Hamburg for many helpful and interesting discussions. The comments of two reviewers were particulary helpful in improving this manuscript. This work was supported by the German Bundesministerium für Bildung, Wissenschaft, Forschung und Technologie (BMBF) as part of the Klimaschwerpunkt "Spurenstoffkreisläufe" and, in part, by NASA's Atmospheric Chemistry Program.

\section{References}

Alm, J., A. Talanov, S. Saarnio, J. Silvola, E. Ikkonen, H. Aaltonen, H. Nykänen, and P. J. Martikainen, Reconstruction of the carbon balance for microsites in a boreal oligotrophic pine fen, Finland, Oecologia, 110, 423-431, 1997.

D'Ans, and E. Lax, Taschenbuch für Chemiker und Physiker, Band I, Springer-Verlag, New York, 1967.

Baker-Blocker, A., T. M. Donahue, and K. H. Mancy, Methane flux from wetland areas, Tellus, 29, 245-250, 1977.

Bartlett, K. B., and R. C. Harriss, Review and assessment of methane emissions from wetlands, Chemosphere, 26 (1-4), 261-320, 1993.

Bartlett, K. B., P. M. Crill, J. A. Bonassi, J. E. Richey, and R. C. Harriss, Methane flux from the Amazon floodplain: Emissions during rising water, J. Geophys. Res., 95(D10), 16,773-16,788, 1990.

Bartlett, K. B., P. M. Crill, R. L. Sass, R. C. Harriss, and N. B. Dise, Methane emissions from tundra environments in the Yukon-Kuskokwim delta, Alaska, J. Geophys. Res., 97(D15), 16,645-16,660, 1992.

Beerling, D.J., and W.P. Quick, A new technique for estimating rates of carboxylation and electron transport in leaves of $\mathrm{C} 3$ plants for use in dynamic global vegetation models, Global Change Biol., 1, 289-294, 1995.

Bender, $\mathrm{M}$., and $\mathrm{R}$. Conrad, Kiretics of $\mathrm{CH}_{4}$ oxidation in oxic soils exposed to ambient air or high $\mathrm{CH}_{4}$ mixing ratios, FEMS Microbiol. Ecol., 101, 261-270, 1992.

Boon, P. I., and B. K. Sorrell, Methane flux from an Australian floodplain wetland: The importance of emergent macrophytes, J. N. Am. Benthological Soc., 14(4), 582-598, 1995.

Bridgham, S. D., and C. J. Richardson, Mechanisms controlling soil respiration $\left(\mathrm{CO}_{2}\right.$ and $\left.\mathrm{CH}_{4}\right)$ in southern peatlands, Soil Biol. Biochem., 24(11), 1089-1099, 1992.

Bubier, J. L., T. R. Moore, L. Bellisario, N. T. Comer, and P. M. Crill, Eco- 
logical controls on methane emissions from a northern peatland complex in the zone of discontinuous permafrost, Manitoba, Canada, Global Biogeochem. Cycles, 9(4), 455-470, 1995.

Cao, M., S. Marshall, and K. Gregson, Global carbon exchange and methane emission from natural wetlands: Application of a process-based model, J. Geophys. Res., 10I(D9), 14,399-14,414, 1996.

Chanton, J. P., and J. W. H. Dacey, Effects of vegetation on methane flux, reservoirs, and carbon isotopic composition, in Trace Gas Emissions by Plants, edited by T. D. Sharkey, E. A. Holland, and H. A. Mooney, pp. 65-92, Academic, San Diego, Calif., 1991.

Chanton, J. P., C. S. Martens, C. A. Kelley, P. M. Crill, and W. J. Showers, Methane transport mechanisms and isotopic fractionation in emergent macrophytes of an Alaskan tundra lake, J. Geophys. Res., 95(D15), $16,681-16,688,1992 a$.

Chanton, J. P., G. J. Whiting, W. J. Showers, and P. M. Crill, Methane flux from Peltranda Virginica: Stable isotope tracing and chamber effects, Global Biogeochem. Cycles, 6(1), 15-31, 1992b.

Chanton, J. P., J. E. Bauer, P. A. Glaser, D. E. Siegel, C. A. Kelley, S. C. Tyler, E. H. Romanowicz, and A. Lazrus, Radiocarbon evidence for the substrates supporting methane formation within northern Minnesota peatlands, Geochim. Cosmochim. Acta, 59(17), 3663-3668, 1995.

Christensen, T. R., S. Jonasson, T. V. Callaghan, and M. Havström, Spatial variation in high-latitude methane flux along a transect across Siberian and European tundra environments, J. Geophys. Res., 100(D10), 21,035-21,045, 1995.

Clein, J. S., and J. P. Schimel, Microbial activity of tundra and taiga soils at sub-zero temperatures, Soil Biol. Biochem., 27(9), 1231-1234, 1995.

Conrad, R., Control of methane production in terrestrial ecosystems, in $E x$ change of Trace Gases Between Terrestrial Ecosystems and the Atmosphere, edited by M. O. Andreae and D. S. Schimel, pp. 39-58, John Wiley, New York, 1989.

Crill, P. M., K. B. Bartlett, R. C. Harriss, E. Gorham, E. S. Verry, D. I. Sebacher, L. Madzar, and W. Sanner, Methane flux from Minnesota peatlands, Global Biogeochem. Cycles, 2(4), 371-384, 1988.

Dacey, J. W. H., and M. J. Klug, Methane efflux from lake sediments through water lilies, Science, 203, 1253-1254, 1979.

Devol, A. H., J. E. Richey, B. R. Forsberg, and L. A. Martinelli, Seasonal dynamics in methane emissions from the Amazon river floodplain to the troposphere, J. Geophys. Res., 95(D10), 16,417-16,426, 1990.

Dickinson, R. E., A. Henderson-Sellers, and P. J. Kennedy, Biosphere-atmosphere transfer scheme (BATS) version le as coupled to the NCAR community climate model, NCAR Tech. Note NCAR/TN-387+STR, Nat. Cent. for Atmos. Res., Boulder, Colo., 1993.

Dise, N. B., Methane emission from Minnesota peatlands: Spatial and seasonal variability, Global Biogeochem. Cycles, 7(1), 123-142, 1993.

Dise, N. B., E. Gorham, and E. S. Verry, Environmental factors controlling methane emissions from peatlands in Northem Minnesota, J. Geophys. Res., 98(D6), 10,583-10,594, 1993.

Dise, N. B., Winter fluxes of methane from Minnesota peatlands, Biogeochemistry, 17, 71-83, 1992.

Dunfield P., R. Knowles, R. Dumont, and T. R. Moore, Methane production and consumption in temperate and subarctic peat soils: Response to temperature and pH, Soil Biol. Biochem., 25(3), 321-326, 1993.

Fowler, D., K. J. Hargreaves, U. Skiba, R. Milne, M. S. Zahniser, J. B. Moncrieff, I. J. Beverland, and M. W. Gallagher, Measurements of $\mathrm{CH}_{4}$ and $\mathrm{N}_{2} \mathrm{O}$ fluxes at the landscape scale using micrometeorological methods, Philos. Trans. R. Soc. London, Ser. A, 35I(1696), 339-356, 1995.

Frolking, S., and P. Crill, Climate controls on temporal variability of methane flux from a poor fen in southeastern New Hampshire: Measurement and modeling, Global Biogeochem. Cycles, 8(4), 385-397, 1994.

Funk, D. W., E. R. Pullman, K. M. Peterson, P. M. Crill, and W. D. Billings, Influence of water table on carbon dioxide, carbon monoxide, and methane fluxes from taiga bog microcosms. Global Biogeochem. Cycles. 8(3), 271-278, 1994

Gerard, G., and J. Chanton, Quantification of methane oxidation in the rhizosphere of emergent aquatic macrophytes: Defining upper limits, Biogeochemistry, 23, 79-97, 1993.

Happell, J. D., J. P. Chanton, G. J. Whiting, and W. J. Showers, Stable isotopes as tracers of methane dynamics in Everglades marshes with and without active populations of methane oxidizing bacteria, J. Geophys. Res., 98(D8), 14,771-14,782, 1993.

Hein, R., P. J. Crutzen, and M. Heimann, An inverse modeling approach to investigate the global atmospheric methane cycle, Global Biogeochem. Cycles, $11(1), 43-76,1997$.

Heyer, J., Der Kreislauf des Methans, Akademie-Verlag, Berlin, 1990.

Hillel, D., Introduction Into Soil Physics, Academic, San Diego, Calif., 1982.

Holzapfel-Pschorn, A., R. Conrad, and W. Seiler, Effects of vegetation on the emission of methane from submerged paddy soils, Plant Soil, 92 . 223-233, 1986.

Houghton, J.T. (Ed.), Climate Change 1995: The Science of Climate Change, Cambridge Univ. Press, New York, 1996.

Kaltofen, R., R. Opitz, K. Schuhmann, and J. Ziemann, Tabellenbuch der Chemie, VEB Deutscher Verlag für Grundstoffindustrie, Leipzig, 1975.

Keller, M., Biological sources and sinks of methane in tropical habitats and tropical atmospheric chemistry, dissertation, cooperative thesis 126 , Princeton Univ., Princeton, N.J., 1990.

Kettunen, A., and V. Kaitala, Modelling methane emissions from boreal peatlands, in Northern Peatlands in Global Climate Change, Proceedings of the International Workshop Academy of Finland, Helsinki, edited by R. Laiho, J. Laine, and H. Vasander, 277-281, 1996.

Kettunen, A., V. Kaitala, A. Lehtinen, A. Lohila, J. Alm, J. Silvola, and P.J. Martikainen, Methane production and oxidation potentials in relation to water table fluctuations in two boreal mires, Soil Biol. Biochem., 31, 1741-1749, 1999.

Klinger, L. F., P. R. Zimmerman, J. P. Greenberg, L. E. Heidt, and A. B. Guenther, Carbon trace gas fluxes along a successional gradient in the Hudson Bay lowland, J. Geophys. Res., 99(D1), 1469-1494, 1994.

Knorr, W., Satellite remote sensing and modelling of the global $\mathrm{CO}_{2} \mathrm{ex}-$ change of land vegetation: A sythesis study, dissertation, Examensarbeit 49, Max-Planck-Inst. für Meteorol., Hamburg, Germany, 1997.

Knoblauch, C., Bodenkundlich-mikrobiologische Bestandsaufnahme zur Methanoxidation in einer Flußmarsch der Tide-Elbe, diploma thesis, Univ. of Hamburg, Hamburg, Germany, 1994.

Krumholz, L. R., J. L. Hollenback, S. J. Roskes, and D. B. Ringelberg, Methanogenesis and methanotrophy within a Sphagnum peatland FEMS Microbiol. Ecol., 18(3), 215-224, 1995.

Lelieveld, J., P. J. Crutzen, and F. J. Dentener, Changing concentration, lifetime and climate forcing of atmospheric methane, Tellus, Ser. B, $5 O B, 128-150,1998$.

Melloh, R. A., and P. M. Crill, Winter methane dynamics in a temperate peatland, Global Biogeochem. Cycles, 10(2), 247-254, 1996.

Moore, T. R., and M. Dalva, Methane and carbon dioxide exchange potentials of peat soils in aerobic and anaerobic laboratory incubations, Soil Biol. Biochem., 29(8), 1157-1164, 1997.

Moore, T. R., and N. T. Roulet, Methane flux: Water table relations in northern wetlands, Geophys. Res. Lett., 20(7), 587-590, 1993.

Morrissey, L. A., and G. P. Livingston, Methane emissions from Alaska arctic tundra: An assessment of local spatial variability, J. Geophys. Res., 97(D15), 16,661-16,670, 1992.

Nouchi, I., and S. Mariko, Mechanism of methane transport by rice plants, in Biogeochemistry of Global Change, edited by R. S. Oremland, pp. 336-352, Chapman and Hall, New York, 1993.

Potter, C. S., An ecosystem simulation model for methane production and emission from wetlands, Global Biogeochem. Cycles, 11(4), 495-506, 1997.

Press, W. H., S. A. Teukolsky, W. T. Vetterling, and B. P. Flannery, Numerical Recipes in FORTRAN: The Art of Scientific Computing, Cambridge Univ. Press, New York, 1992.

Roeckner, E., K. Arpe, L. Bengtsson, M. Christoph, M. Claussen, L. Dümenil, M. Esch, M. Giorgetta, U. Schlese, U. Schulzweida, The atmospheric general circulation model ECHAM4: Model description and simulation of present-day climate, Rep. 218,90 pp., Max-Planck-Institut für Meteorologie, Hamburg, Germany, 1996.

Roulet, N. T., R. Ash, and T. R. Moore, Low boreal wetlands as a source of atmospheric methane, J. Geophys. Res., 97(D4), 3739-3749, 1992.

Roulet, N. T., R. Ash, W. Quinton, and T. Moore, Methane flux from drained Northern peatlands: Effect of a persistent water table lowering on flux, Global Biogeochem. Cycles, 7(4), 749-769, 1993.

Saamio, S., J. Alm, J. Silvola, A. Lohila, H. Nykänen, and P. J. Martikainen, Seasonal variation in $\mathrm{CH}_{4}$ emissions and production and oxidation potentials at microsites of an oligotrophic pine fen, Oecologia, 110 , 414-422, 1997

Scheffer, F., and P. Schachtschabel, Lehrbuch der Bodenkunde, Ferdinand Enke Verlag, Stuttgart, Germany, 1982. 
Schimel, J. P., Plant transport and methane production as controls on methane flux from arctic wet meadow tundra, Biogeochemistry, 28, 183-200, 1995.

Schipper, L. A., and K. R. Reddy, Determination of methane oxidation in the rhizosphere of Sagittaria lancifolia using methyl fluoride, Soil Sci. Soc. Am. J., 60, 611-616, 1996.

Schlesinger, W. H., Biogeochemistry, An Analysis of Global Change, Academic, San Diego, Calif., 1991.

Schütz, H., W. Seiler, and R. Conrad, Processes involved in formation and emission of methane in rice paddies, Biogeochemistry, 7, 33-53, 1989.

Sebacher, D. I., R. C. Harriss, K. B. Bartlett, S. M. Sebacher, and S. S. Grice, Atmospheric methane sources: Alaskan tundra bogs, an alpine fen, and a subarctic boreal marsh, Tellus, Ser. B, 38B, 1-10, 1986.

Shafer, N. E., and R. N. Zare, Through a beer glass darkly, Phys. Today, 48$52,1991$.

Shannon, R. D., and J. R. White, A three-year study of controls on methane emissions from two Michigan peatlands, Biogeochemistry, 27, 35-60, 1994.

Shannon, R. D., J. R. White, J. E. Lawson, and B. S. Gilmour, Methane efflux from emergent vegetation in peatlands, $J$. Ecol., 84(2), 239-246, 1996.

Sundh, I., M. Nilsson, G. Granberg, and B. H. Svensson, Depth distribution of microbial production and oxidation of methane in northern boreal peatlands, Microb. Ecol., 27, 253-265, 1994.

Torn, M. S., and F. S. Chapin III, Environmental and biotic controls over methane flux from arctic tundra, Chemosphere, 26, 357-368, 1993.

Valentine, D. W., E. A. Holland, and D. S. Schimel, Ecosystem and physiological controls over methane production in northern wetlands, J. Geophys. Res., 99(D1), 1563-1571, 1994.

Waddington, J. M., N. T. Roulet, and R. V. Swanson, Water table control of $\mathrm{CH}_{4}$ emission enhancement by vascular plants in boreal peatlands, $J$. Geophys. Res., 101(D17), 22,775-22,785, 1996.

Walter, B.P., Development of a process-based model to derive methane emissions from natural wetlands for climate studies, dissertation, Examensarbeit 60, Max-Planck-Instit. für Meteorol., Hamburg, Germany, 1998.
Walter, B. P., M. Heimann, R. D. Shannon, and J. R. White, A processbased model to derive methane emissions from natural wetlands, Geophys. Res. Lett., 23(25), 3731-3734, 1996.

Wassmann, R., U. G. Thein, M. J. Whiticar, H. Rennenberg, W. Seiler, and W. J. Junk, Methane emissions from the Amazon floodplain: Characterization of production and transport, Global Biogeochem. Cycles, 6(1), 3-13, 1992.

Watson, A., K. D. Stephen, D. B. Nedwell, and J. R. M. Arah, Oxidation of methane in peat - Kinetics of $\mathrm{CH}_{4}$ and $\mathrm{O}_{2}$ removal and the role of plant roots, Soil Biol. Biochem., 29(8), 1257-1267, 1997.

Westermann, P., Temperature regulation of methanogenesis in wetlands, Chemosphere, 26, 321-328, 1993.

Whalen, S. C., and W. S. Reeburgh, Interannual variations in tundra methane ernissions: A four-year time series at fixed sites, Global Biogeochem. Cycles, 6(2), 139-159, 1992.

Whiting, G. J., and J. P. Chanton, Plant-dependent $\mathrm{CH}_{4}$ emission in a subarctic Canadian fen, Global Biogeochem. Cycles, 6 (3), 225-231, 1992.

Whiting, G. J., and J. P. Chanton, Primary production control of methane emission from wetlands, Nature, 364, 794-795, 1993.

Whiting, G. J., J. P. Chanton, D. S. Bartlett, and J. D. Happell, Relationships between $\mathrm{CH}_{4}$ emission, biomass, and $\mathrm{CO}_{2}$ exchange in a subtropical grassland, J. Geophys. Res., 96(D7), 13,067-13,071, 1991.

Wilson, M.F., and A. Henderson-Sellers, A global archive of land cover and soils data for use in general circulation models, J. Clim., 5, 119-143, 1985.

Yavitt, J. B., and A. K. Knapp, Methane emission to the atmosphere through emergent cattail (Thypha latifolia L.) plants, Tellus, Ser. B, $47 B, 521-534,1995$.

M. Heimann, Max-Planck-Institut für Biogeochemie, Postfach 100164, 07701 Jena, Germany. (martin.heimann@bgc-jena.mpg.de.)

B.P. Walter, Columbia University/NASA Goddard Institute for Space Studies, 2880 Broadway, New York, NY 10025. (bwalter@giss.nasa.gov.)

(Received July 26, 1999; revised October 22, 1999; accepted November 8, 1999.) 